IZA DP No. 4914

SES Health Gradients during the Epidemiological Transition: The Case of China

Xiaoyan Lei

Nina Yin

Yaohui Zhao

April 2010 


\title{
SES Health Gradients during the Epidemiological Transition: The Case of China
}

\author{
Xiaoyan Lei \\ Peking University \\ and IZA \\ Nina Yin \\ Toulouse School of Economics \\ Yaohui Zhao \\ Peking University \\ and IZA
}

Discussion Paper No. 4914

April 2010

IZA

P.O. Box 7240

53072 Bonn

Germany

Phone: +49-228-3894-0

Fax: +49-228-3894-180

E-mail: iza@iza.org

Any opinions expressed here are those of the author(s) and not those of IZA. Research published in this series may include views on policy, but the institute itself takes no institutional policy positions.

The Institute for the Study of Labor (IZA) in Bonn is a local and virtual international research center and a place of communication between science, politics and business. IZA is an independent nonprofit organization supported by Deutsche Post Foundation. The center is associated with the University of Bonn and offers a stimulating research environment through its international network, workshops and conferences, data service, project support, research visits and doctoral program. IZA engages in (i) original and internationally competitive research in all fields of labor economics, (ii) development of policy concepts, and (iii) dissemination of research results and concepts to the interested public.

IZA Discussion Papers often represent preliminary work and are circulated to encourage discussion. Citation of such a paper should account for its provisional character. A revised version may be available directly from the author. 


\section{ABSTRACT \\ SES Health Gradients during the Epidemiological Transition: The Case of China*}

The epidemiological transition, which has already passed the developed world, is still progressing in many developing countries. A particular problem associated with this transition is the under-diagnosis and lack of treatment of chronic diseases, and these may exhibit SES gradients and exacerbate social inequality. Using hypertension as an example and data from China (CHNS), we find that the prevalence of hypertension in China is already close to levels in developed countries, under-diagnosis is pervasive, treatment is rare, and failure to control is widespread. Consistent with the literature, we find no income and education gradients in the prevalence of hypertension. However, there are strong education gradients in diagnosis and treatment in urban areas. The income gradients in all aspects of hypertension are relatively weak and sometimes nonexistent. Interestingly, we find that access to health care does not contribute to the diagnosis of hypertension, nor does it aid much in the treatment and control of hypertension. Our results suggest that the epidemiological transition has indeed occurred, but both the Chinese public and its health care system are ill-prepared. There is an urgent need to educate the public on chronic illnesses, and to raise the quality of health care so that patients receive proper diagnoses and guidance on how to treat and control those chronic illnesses.

JEL Classification: epidemiological transition, under-diagnosis, SES health gradients

Keywords: $\quad I 10$

Corresponding author:

Yaohui Zhao

China Center for Economic Research

Peking University

Beijing 100871

China

E-mail: yhzhao@ccer.edu.cn

\footnotetext{
* The excellent research assistance of $\mathrm{Yi}$ Chen is greatly appreciated. We would also like to thank James Smith and Karen Eggleston for their invaluable comments.
} 


\section{Introduction}

The epidemiological transition, characterized by a shift in the disease profile from acute infectious diseases to chronic and degenerative diseases, is currently underway in most developing countries (Gribble ad Preston, 1993). China is no exception. With a rapid decline in fertility and falling infant and child mortality rates, the population is aging rapidly. The disease profile thus increasingly reflects that of an older population. The transition is accelerated by a rapid shift in dietary intake from malnutrition to over-nutrition, due to economic growth and poverty reduction (Popkin et al., 1993; Wagstaff et al., 2003). As evidence of this transition, vascular disease has recently emerged as a leading cause of death among Chinese adults (He et al., 2005).

The epidemiological transition poses special challenges to the health system. Unlike with acute infectious diseases which are easy to recognize, it is easy to overlook the symptoms of chronic and degenerate diseases until there are in their advanced stages. In addition, unlike acute infectious diseases which have been around as long as humans have, chronic diseases are a relatively new phenomenon, making them harder to recognize. In China, both demographic transition and economic growth occurred at breakneck speeds, resulting in a particularly fast epidemiological transition. Therefore, under-diagnosis may be especially serious. The first goal of this paper is to confirm this hypothesis.

In the midst of the epidemiological transition, when the general public lacks experience in dealing with emergent diseases, it is likely that the better endowed are more successful in overcoming these diseases, either through better diagnoses or better treatment and control. If this is true, then there is an added health component to the already large income inequality in developing countries. Using hypertension as an example, the second goal of this paper is to investigate whether the actual prevalence, awareness, treatment, and control of newly emerging chronic diseases have an SES gradient, and what roles health behavior and access to health services play in any aspect of those chronic diseases. We use income and education as indicators of SES because they are the defining indicators of socioeconomic status in the literature, and are 
distributed unequally within society. Hypertension is chosen because it is easier to physically measure (in the form of blood pressure) than diabetes or lipoprotein in a household survey. ${ }^{1}$

Known as a "silent killer," hypertension is a serious chronic disease. It kills by placing extra stress on the heart, leading to coronary artery diseases and precipitating strokes. In recent decades, the number of hypertension cases has skyrocketed, growing from 30 million cases in 1960 to 94 million in 1990 (He et al., 1996). One study conducted between 2000-2001 of a nationally representative sample of 15,540 adults aged 35 to 74 years, showed that the prevalence rate of hypertension was 27.2 percent, exceeding that of many developing countries, and similar to the rates often seen in industrialized countries (Gu et al., 2002). Despite being a serious risk factor for vascular diseases, hypertension is preventable and treatable, and successful prevention and control of hypertension can significantly reduce premature mortality (JNC7, 2004). However, hypertension can be easily overlooked. It has no major symptoms except when blood pressure becomes excessively high. Hypertension can also be difficult to control - one study found that blood pressure goals may be difficult to achieve in as many as 40 percent of patients. Resistant or difficult-to-control systolic hypertension is more common in patients over the age of 60 years than in younger patients (Moser and Setaro, 2006).

The paper proceeds as follows: Section 2 describes the China Health and Nutrition Survey (CHNS), the dataset used for this study, and shows statistics on the prevalence of hypertension and the degrees of under-diagnosis and lack of treatment and control. Section 3 presents regression results on the SES gradients on the prevalence, awareness, treatment, control, and eventual rate of uncontrolled hypertension. Section 4 concludes with policy implications.

\section{Data and Descriptive Statistics}

The CHNS is a longitudinal household survey, conducted in nine Chinese provinces: Guangxi, Guizhou, Heilongjiang, Henan, Hubei, Hunan, Jiangsu, Liaoning, and Shandong. The survey contains an extensive set of questions on health status and health behaviors, as well as socioeconomic statuses of the respondents. The community survey provides a detailed picture of the local environment in which CHNS households and individuals live, including health services

\footnotetext{
${ }^{1}$ Our data contain measures of blood pressures as well as self-reported hypertension so that we can examine the issue of awareness and control.
} 
infrastructure such as distances to medical facilities, and number of doctors. Waves 2004 and 2006 are used in our study, and subjects are restricted to older individuals aged 45 to 80, an age group more likely to be affected by hypertension.

We use actual, not self-reported prevalence of hypertension in this paper, which is defined through physical examination accompanying the survey. Blood pressures were taken three times by medical professionals. As is standard in the medical literature, we use the average of the second and the third blood pressure readings. Hypertension is defined the same as in the literature: systolic blood pressure greater than or equal to $140 \mathrm{~mm} \mathrm{Hg}$, or corresponding diastolic blood pressure greater than or equal to $90 \mathrm{~mm} \mathrm{Hg}$. Additionally, if a subject yields normal blood pressure readings but is taking anti-hypertensive medication at the time, we consider him/her a hypertensive patient ${ }^{2}$.

Awareness of hypertension is defined within the subset of the population that is hypertensive as described in the previous paragraph. This information is directly obtained from the survey question, “Did a doctor ever tell you that you were hypertensive?” If the answer to this question is "Yes," then the respondent is considered aware of the condition; otherwise he/she is considered to be unaware. In other words, “awareness” is acknowledgement of one’s condition when the condition is present.

Treatment and successful control are defined only among diagnosed hypertension patients. If a hypertensive patient is currently taking anti-hypertension medicine, he/she is considered to be under treatment. If the blood pressure readings of a hypertensive patient are within the normal range, then his/her hypertension is under successful control.

The final outcome we examine is uncontrolled hypertension. It indicates a subject having hypertension readings regardless of awareness or medicating status. This includes those who had never been diagnosed, those who had been diagnosed but not treated, and those who had been diagnosed and treated but not under control. It is the outcome after all possible actions had been taken by the individuals to get diagnosed with or to control hypertension, and is ultimately responsible for causing cardiovascular disease. Under this definition, a once-diagnosed patient

\footnotetext{
2 This definition follows JNC 6, which is adopted by most of the literature. An alternative way to define hypertension is to sum over those who are self-reported and those who are clinically diagnosed. We tried the alternative way and found little difference in the number of hypertensive patients defined in these two ways, and thus no difference in our results.
} 
does not belong to this category if blood pressure is successfully controlled. An undiagnosed patient will be considered to be uncontrolled, because no action to control the hypertension is being taken. The difference between this term and the aforementioned "control among diagnosed hypertension patients" is that "uncontrolled hypertension" is defined among the whole sample, whereas the other is defined over the subset of hypertensive patients who are aware of their conditions. In short, uncontrolled hypertension is a summary health measure revealing the degree to which people actually suffer, and is the heath condition that we are ultimately concerned with.

The CHNS is a panel survey. The overall sample of people aged 45 to 80 in waves 2004 and 2006 is 10,737. After deleting observations without objective measures of hypertension, we are left with 10,269 observations. Some hypertensive patients underwent physical examinations in wave 2000 (2004), and as a result were informed of their condition by the survey; thus their awareness of hypertension in the subsequent wave 2004 (2006) was contaminated by the survey. We exclude 325 such observations from our analysis. Our results, however, are not sensitive to this exclusion. After these exclusions, we end up with a total of 9,944 observations. ${ }^{3}$ In addition to the aforementioned variables denoting prevalence, awareness, treatment and control given a diagnosis of hypertension, and ultimate uncontrolled hypertension, we consider socioeconomic characteristics (age, gender, ethnicity, education, marital status, income quartiles), behavioral risk factors (smoking, weight, alcohol consumption), health care access (distance to the nearest medical facility, the availability of health insurance, etc.), and county/city dummies. Detailed definitions of these variables can be found in Appendix Table $2 .{ }^{4}$

We first present basic descriptive statistics of the main explanatory variables then turn our attention to our key hypertension indicators. The first column of Table 1 shows a general picture of the whole sample of people aged 45 to 80 , while the remaining two pairs of columns disaggregate the sample by residency and gender. The significance signs indicate that the characteristic in that row (e.g., age) is significantly different between the two groups of people within that pair (e.g. urban/rural). On average, sample respondents were 58.5 years of age, 47.4 percent were male, and 50.9 percent were residing in urban areas. The mean number of years of schooling was 6.2, with a gap of 2.4 years between urban and rural residents and 2.7 years

\footnotetext{
${ }^{3}$ For more detailed information on restriction rules and number of observations, please see Appendix Table 1.

${ }^{4}$ Our definition of urban vs. rural areas deviates a little from the definition provided in the data. We defined county town as urban instead of rural as CHNS does. And suburban village is defined as rural, which is also different from CHNS.
} 
between men and women. The mean per capita income was 7008.9 Yuan, and urban income was 86 percent higher than rural income. ${ }^{5}$ Most (85.9 percent) were married at the time. A substantial proportion of men exhibited risky behavior: 34.9 percent reported having ever smoked and 17.4 percent reported heavy alcohol consumption. ${ }^{6}$ Women hardly smoked or drank heavily. Overall, 25.8 percent were overweight $\left(30>\mathrm{BMI} \geq 25.0 \mathrm{~kg} / \mathrm{m}^{2}\right)$ and 4.9 percent were obese $(\mathrm{BMI} \geq 30.0$ $\mathrm{kg} / \mathrm{m}^{2}$ ) with a higher rate among urban residents and women. ${ }^{7} 41.2$ percent had medical insurance, 14.8 percentage points more common among urban than rural residents. ${ }^{8}$ To gauge access to medical services, we consider several measurements. The first is whether the nearest facility to the community is a hospital beyond county level, representing the quality of the facility. The second is the distance to the nearest medical facility, which represents convenience of approaching medical services. The average distance is 0.19 kilometers. The nearest health facilities used in the rural areas are less likely to be at county level or above and more likely to be within a community, and the average distance between the facility and the community center is shorter in general. Since a substantial fraction (68.5 percent) of the nearest medical facilities are located within the community, and thus have a distance of zero, in regression models we use a dummy variable to capture this difference.

Because urban/rural differences dominate gender differences among the main SES variables, in this paper we focus on urban-rural differences by running separate analyses for the two areas, but discuss gender differences along the way.

Table 2 reports basic indicators about hypertension. As Panel A shows, 12.4 percent of respondents had been diagnosed with hypertension, but the actual prevalence rate was as high as 32.7 percent, and the uncontrolled hypertension rate was 29.1 percent, meaning that these people were still suffering from hypertension at the time the survey was administered. The huge difference between diagnosis and actual prevalence was caused by the low rate of awareness: Of all the hypertensive patients in our sample, only 37.9 percent were aware of their condition. 77.0 percent of those who were aware were medicated with anti-hypertension medicine, but a mere 11.0 percent of those aware had their blood pressures controlled successfully.

\footnotetext{
5 All incomes are evaluated at 2006 prices.

${ }^{6}$ Heavy drinking is defined as drinking 3 times or more per week.

7 Body Mass Index is defined as $B M I=$ weight $(\mathrm{kg}) / \mathrm{height}^{2}\left(\mathrm{~m}^{2}\right)$ (Inoue et al., 2002).

8 The difference is much greater if wave 2004 (47.2 versus 20.2) is considered alone; this change is mainly caused by the spread of New Corporate Medical Scheme in rural site since 2003.
} 
The lack of awareness and control of chronic illnesses is not unique to China. They occur even in developed countries such as the United States. As expected, rates of awareness and control of chronic diseases are much lower in China than in the United States, at least in the case of hypertension. Between 1999-2000, 68.9 percent of hypertensive Americans were aware of their condition, 54 percent higher than in China. 31.0 percent of cases were under control in the U.S., nearly three times higher than in China (Hajjar and Kotchen, 2003). ${ }^{9}$ The differences can partly attribute to the different stages of epidemiological transition. As the public gradually becomes aware of the diseases, diagnosis improves. Smith (2007) found that diagnoses of diabetes, another common and serious illness afflicting the elderly, have improved significantly in the U.S. over a period of 25 years.

Figure 1 shows diagnosed prevalence rate, actual prevalence rate and uncontrolled rate of hypertension in subjects aged 20 to 80 . As expected, all three indicators rise with age, with actual prevalence rate being the highest and diagnosed prevalence rate the lowest. The discrepancy between actual prevalence and diagnosed prevalence of hypertension increases with age as a result of rapid increases in actual hypertension prevalence in comparison to diagnosis. The uncontrolled hypertension rate is identical to the actual prevalence rate before age 50, and the difference between the two measures remains very small thereafter. This suggests that the lack of effective control is a serious problem in all ages, and is even more serious among younger people.

Figure 2 shows age patterns of awareness, treatment and control more clearly: older patients are more aware of their condition and more likely to get it treated than younger ones once they are aware, but the rate of control, conditional on awareness, barely changes across age, suggesting that it is much more difficult to control hypertension than to learn about it. Control rate even appears to have a slightly declining trend, suggesting that it is even more difficult for older people to get their condition under control.

Panel A of Table 2 also presents rural/urban and male/female differences in the diagnosis, prevalence, awareness, treatment and control of hypertension. The diagnosis is much lower than actual prevalence among all groups, while the urban/rural difference in the former is larger than

9 Awareness and control rates in the UK seem surprisingly low - the awareness rate being 46.2 percent and the control rate being 9.3 percent in 1998 (Primatesta and Poulter, 2001). Johnston et al. (2009) reports an extremely low awareness rate of hypertension in England (about 15percent), but the authors measure awareness differently. 
that in the latter. Consistent with Hou (2008), urban residents are more hypertensive (36.8 percent urban versus 28.5 percent rural), better aware of their condition (46.2 percent versus 26.8 percent), more likely to get their condition treated (80.7 percent versus 68.5) and controlled (14.0 percent versus 6.9 percent) given awareness. Although the share of people with uncontrolled hypertension is higher among the urban than the rural (31.6 percent versus 26.6 percent), because of better awareness and control among urban subjects, the gap is much smaller than that of actual prevalence.

As for differences between the genders, men are more hypertensive than women (34.0 percent versus 31.5 percent), are significantly less aware if they are hypertensive (32.5 percent versus 43.2 percent), are less likely to seek treatment (73.7 percent versus 79.4 percent), and have a lower control rate (9.8 percent versus 12.1 percent) given awareness. As a result, the gender gap in the uncontrolled rate (30.7 percent versus 27.7 percent) is similar to that of the prevalence rate.

Panels B and C of Table 2 further disaggregate by residence and sex. We observe that urban men are the most hypertensive (38.3 percent), and rural women the least hypertensive (27.4 percent). In contrast, urban women have the highest rate of awareness (51.4 percent) and control (15.2 percent), and rural men the lowest rate of awareness (21.9 percent) and control (6.0 percent).

\section{Estimation Results}

\subsection{Actual Prevalence of Hypertension}

Table 3 illustrates the probit estimates of actual prevalence of hypertension based on SES, risk factors and access to medical facilities for elderly people aged 45 to 80. Because urban and rural patterns are very different, we run separate estimates for urban and rural data. For both urban and rural estimations, we present one model with and one without health behavior and health care access indicators. As most of the explanatory variables are dummy variables, average marginal effects are calculated and reported.

Age is important in explaining hypertension across all models. Model 1 shows that as an urban person ages by 1 year, his/her probability of being hypertensive increases by 1.2 
percentage points. Since the average rate of hypertension in the urban population is 36.8 percent in our sample, this represents a $3.3(=1.2 / 36.8)$ percent increase in risk. In rural areas, aging by 1 year increases the probability of being hypertensive by 1.1 percentage points, resulting in a 3.9 (1.1/28.5) percent increase in risk. We try to also include quadratic terms, but there is little difference in results. In both urban and rural areas, men are more likely to be hypertensive. In urban areas, this gender difference is fully explained with the inclusion of health behaviors and access variables. In rural areas, however, the gender difference is reinforced after this inclusion, indicating that the gender difference in behavior and access are different in these two areas.

We find no education and income gradients. This is surprising at first sight because most studies do find SES health gradients. However, the literature on hypertension in developing countries has reported the lack of an SES gradient (Witoelar, Strauss and Sikoki, 2009). The likely explanation is that cardio-vascular diseases originate more from in-utero and childhood conditions than from present-day socio-economic conditions (Barker, 1997), and at the time when these respondents were young the SES conditions in China were more or less equal.

In all regression models we present, causality may run both ways. Liu et al. (2008) has shown that good health is associated with higher income. Additionally, there may be other omitted variables at the local and household levels that affect both SES status and health outcomes. All regressions discussed so far have included county/city fixed effects. ${ }^{10}$ Not being able to completely control for endogeneity, we will refrain from making strong causal interpretations.

Models 2 and 4 include risk behaviors and variables indicating access to health care. The coefficients of risk factors are different between urban and rural areas. In rural areas, former smokers are no more hypertensive than lifetime non-smokers, and current smokers are the least likely to be hypertensive, suggesting that people who remain smoking are likely those who are relatively healthier. Being overweight or obese have large positive effects on actual prevalence — an overweight person is 15.3 percentage points, or 42 percent $(=15.3 / 36.8)$ more likely to be hypertensive than a person of normal weight in urban areas, and even greater effects are found in rural samples (17.5 percentage points, or 61.4 percent). The effects of obesity are much larger -

\footnotetext{
${ }^{10}$ We also estimate with community fixed-effects models and find very similar results. Because with community fixed effects, we are not able to examine the effects of community-level variables, we only report results with county fixed-effects.
} 
24.6 and 24.8 percentage points (or 67 and 87 percents) respectively in the urban and rural areas. As projected by the WHO, obesity rates (defined as BMI $>=30 \mathrm{~kg} / \mathrm{m}^{2}$, the same as the definition in our paper) for Chinese men will increase from 1.8 percent in 2005 to 9.4 percent in 2015 and for Chinese women will increase from 2.6 percent to 8.6 percent (WHO, 2009) ${ }^{11}$. Assuming the growth rate of obesity in our study population is 6.8 percentage points, or the average of the two growth rates, all other things being equal, this will result in an increase in hypertension prevalence by 1.7 percentage points $(=6.8 * 0.246$ and $6.8 * 0.248)$ among both the urban and rural populations (from 36.8 to 38.5 percent and 28.5 percent to 30.2 percent respectively).We also see a positive association between heavy drinking and prevalence in both areas. ${ }^{12}$

Whether or not one has health insurance is not correlated with hypertension prevalence. A natural explanation is that health insurance is used as treatment rather than preventive care, so unless moral hazard is strong enough to alter health behavior, we do not expect to see a correlation between health insurance and prevalence of hypertension. Measures of medical facilities are generally insignificant with two exceptions. One is a distance measurement for urban residents and the other is the level of medical facility for rural residents. However, both of these have unexpected signs. The farther the nearest facility, the lower the prevalence rate in urban residents; and the higher the grade of the facility, the higher the prevalence rate in rural residents. One possible explanation is selection on residence and medical utilization based on health status: the less healthy may be more likely to live closer to a medical facility and this selection effect is more significant in urban areas because urban residents are more flexible in location selection than their rural counterparts. Meanwhile, less healthy people may also be more likely to choose a medical facility of a higher grade, but as there is greater variation in level of the nearest medical facilities in rural areas, we see a larger selection effect of this kind in rural areas. The other possibility is that since urbanization is a gradient from rural to urban rather than a distinct cut-off, this may capture the gradient in location and adoption of urban sedentary lifestyles, with the anomalous results reflecting rural residents closest to cities and urban residents closest to the countryside. ${ }^{13}$

\footnotetext{
11 See Appendix Table 5.

12 To see how health behavior varies by sex and SES variables, we run a regression of health behavior against sex and a host of SES variable (Appendix Table 4). As expected, health behaviors vary substantially by gender. We also see some variations by education and income.

${ }^{13}$ We thank Karen Eggleston for suggesting this explanation.
} 


\subsection{Awareness of Hypertension}

As discussed earlier, less than half of all hypertensive patients are diagnosed. Even if no SES gradients exist in the prevalence of hypertension, significant SES gradients in diagnosis could cause the less disadvantaged group to receive less medical attention. In this section, therefore, we estimate determinants of awareness of hypertension among hypertensive patients in Table 4 for the urban and rural samples separately. ${ }^{14}$

We first note that older hypertensive patients are more likely to be aware of their conditions. This may be a form of network effect: when peers are diagnosed, they increasingly seek diagnosis of their own conditions as well. Men are much less likely to be aware of their condition than are women, conditional on being hypertensive. Urban men in particular face a tough situation compared to rural men: they are 11.6 percentage points, or 25.1 percent less likely to be aware of their condition than urban women. The gender difference is comparatively smaller in rural areas, but still quite large (10.2 percentage points, or 37.7 percent). Controlling for behavioral and access variables, men are still significantly less likely to be aware of their condition. Marital status does not show a significant effect on awareness. The signs for ethnic minorities are opposite between urban and rural residents: urban minorities are less aware but rural minorities are more aware. Because the composition of ethnic minorities is likely different between urban and rural areas, we merely control for this variable and do not try to interpret this result.

As expected, education is positively correlated with awareness in the urban sample, ${ }^{15}$ but the gradient is quite weak among rural residents with a slight difference between the illiterate (the reference group) and those with a primary school level education. Income gradients also show up for awareness. For urban (rural) residents, the richest quartile are 7.6 (8.0) percentage points (or 16.5 (29.9) percent) more likely to be aware of their condition than those in the $1^{\text {st }}$ quartile.

How do we explain these patterns of education and income gradients of hypertension awareness? Possible candidates are health risk behaviors and access to health care services.

\footnotetext{
14 Because hypertensive patients are a selected sample and the process governing their selection may be different in urban versus rural areas, we must be careful in comparing results between urban and rural models. Nevertheless, the selection does not prevent us from using the hypertensive sample to analyze awareness among hypertensive patients.

15 This result is similar to that in Smith (2007) where the author finds that higher educated patients are more likely to be aware or to be diagnosed of their diabetic condition.
} 
Perhaps people who are obese, are heavy drinkers, or are smokers are more likely to know it when they are hypertensive. Where health services are more accessible, perhaps people are more likely to get physical examinations and learn about their health conditions. Because income and education are correlated with risk behaviors and access to health care services (Appendix Table 4), including these variables is expected to weaken the income and education gradients.

Sure enough, when we include health behavior and access to health care services in Columns 2 and 4 for the urban and the rural samples respectively, income gradients disappear. This implies that the income gradients are fully explained by behavioral and access differences. As for the effects of education, in urban areas, after adding behavior and health care access variables, education remains significant with a slight decline in magnitude; in rural areas, the educational advantage for people with a primary school education remains unchanged. These imply that education has independent effects on the diagnosis of hypertension, most likely through information. The weaker effect of rural education indicates that rural education confers less information on health but it is puzzling as to why this is so.

Being overweight and obese has direct and significant roles in hypertension awareness for both the urban and rural populations. In urban areas, an overweight person is 8.4 percentage points (or 18.1 percent) more likely to be aware of his/her condition; in rural areas, this number is 6.5 percentage points (or 24.3 percent). ${ }^{16}$ For an obese person the numbers are much higher, 20.5 and 25.2 percentage points (or 44.4 and 94.0 percent) in the two areas respectively. A possible explanation for the effect that obesity has is that a high correlation between hypertension and obesity is already public knowledge. Thus, an obese person is more likely to be on the lookout for its emergence. An urban smoker who has quit smoking is significantly more likely to be aware of his/her condition. This causality is likely the reverse: smokers are more likely to quit once they are diagnosed with hypertension. Rural smokers do not show this tendency, however. Interestingly, opposite to obesity and smoking behavior, a heavy drinker is slightly less likely to be aware in the rural area, which could be either due to ignorance of this risk or due to self-selection into drinking (i.e., those who are unaware likely choose to drink heavily).

Because awareness is diagnosis by a doctor, access to medical service is potentially the most important factor contributing to one's awareness. Surprisingly, only distance to the nearest

16 As shown in Table 2, the awareness rates are 46.2 percent and 26.8 percent respectively, in the urban and rural areas. 
medical facility is weakly significant for rural residents; no other indicators are significant. Having medical insurance increases the probability of awareness only in urban areas with marginal significance.

One possible explanation to this puzzle is that clinics and doctors in both urban and rural areas do not routinely test for hypertension during a visit by a patient. We searched for medical regulations and found that testing for blood pressure is required for all inpatient visits, but not for most outpatient visits. At a typical outpatient care unit in large hospitals, there is no nurse taking blood pressure, and doctors usually spend very little time with a patient. ${ }^{17}$ Therefore, unless a patient sees a doctor for a cardiovascular complaint, a doctor is unlikely to test blood pressure. Even in inpatient care, a nurse may not voluntarily tell a patient his/her blood pressure if it is unrelated to the treatment.

To learn whether seeing a doctor contributes to the awareness of hypertension, and by how much, we run a regression of hypertensive awareness and include whether a respondent has had any inpatient or outpatient visits in the previous four weeks. As shown in the bottom of Table 4-1, compared with people who have never had any medical care in the previous 4 weeks, both patients with inpatient and outpatient visits are more likely to be aware of their hypertension, with the effect of the former larger than the latter, suggesting that inpatient visits are indeed more likely to result in blood pressure tests in both urban and rural areas. Not surprisingly, the effects of both outpatient and inpatient visits are smaller in rural than in urban areas, suggesting that doctors in rural areas are less likely to test for blood pressure or tell patients about their condition. However, in terms of magnitude, neither effect is very large. If doctors routinely measure blood pressure and tell patients about it, then the marginal effects should be close to 1; however, they are only between 21.0 and 27.9 percent in our model.

Our results confirm the conclusion by Eggleston et al. (2008) that quality of care in China has room for improvement. The results also have important policy implications: to improve the awareness of diseases, it is not enough to move medical facilities closer to people; attention to specifics of clinical practice should also be paid. ${ }^{18}$ Blood pressure

\footnotetext{
17 The outpatient care in China has been pictured as "three hours of waiting and three minutes seeing by a doctor". http://www.cmda.gov.cn/News/redianhuati/redianhuatiwenzhang/2009-09-18/6275.html

18 Wagstaff et al. (2003) contains an excellent discussion on where the problems in the health care sector are and how to improve service delivery.
} 
should be a part of the routine checkup for any patient over a certain age, and results should be communicated to the patients.

\subsection{Treatment and Control of Hypertension among Diagnosed Hypertension Patients}

Being aware of hypertension does not necessarily imply treatment or control of hypertension. As shown previously in Table 2, the rate of treatment, conditional on awareness is 77 percent (80.7 percent in urban areas and 68.5 percent in rural areas).

Table 5 reports the estimation on treatment and control of hypertension with the sample of hypertensive patients who are aware of their condition, reported in Columns 1-4 and Columns 5-8 respectively. Let us consider treatment first. In the urban areas, older residents are more likely to be treated for hypertension once they are aware of it. However, in rural areas the coefficient of age is insignificant. Getting medical treatment requires both time and financial resources. Under normal conditions, age effect is supposed to be positive because older people have more time to spare than younger people. In China, the rural elderly retire much later. They also have fewer resources available to them to treat hypertension because rural medical insurance usually does not cover chronic diseases such as hypertension. Additionally, given tight budget constraints, rural families may place less importance on the health of the elderly, because they are less productive than younger members of the family.

Among urban residents, men are 12.7 percentage points (15.6 percent) less likely to seek treatment, suggesting that urban men are not only less likely to be aware of their condition, but also less likely to seek treatment even if they are aware of it. This may reflect the relatively high opportunity cost of spending time in seeking medical treatment for urban men. The gender difference is nearly insignificant in rural areas, however.

Looking at the SES variables, we observe strong, positive education gradients in urban areas, but not in rural areas. Income does not matter much for treatment in urban areas and only a weak significance appears in the third quartile of rural residents, with a negative sign. We do not have strong priors as to the sign of these variables because although people with higher education levels and more income can better afford medical care, they also face higher opportunity cost in seeking treatment. 
Looking into behavioral risks is of interest as well. In urban areas, the overweight and obese are more likely to seek treatment, but in rural areas, they are less likely. Heavy drinkers are less likely to seek treatment in both urban and rural areas, possibly because these people are more carefree and are less risk-averse. Smoking behavior does not significantly correlate with decisions to seek treatment, however. None of the facility variables are significant, indicating that medical facilities may not play an important role in increasing hypertension treatment.

We now turn to Columns 5-8 for estimation on control of hypertension among diagnosed patients. As mentioned above (Table 2), the rate for successful control is extremely low. Conditional on awareness, the success rate in controlling hypertension is only 11.0 percent on average, 14.0 percent among the urban sample, and 6.9 percent among the rural sample. Given the difficulty in controlling hypertension, it is interesting to know which factors, if any, make a difference. Columns 5-8 of Table 5 tell us that predicting control is equally difficult. Hardly anything in our model has a significant sign in the urban sample. No educational difference is observed either in urban or in rural areas. Several variables show up as being significant in the rural sample. Age is negative and significant. Those with a higher income, especially in the third quartile, are more likely to have their condition under control.

Despite the fact that they enjoy higher awareness and treatment rates, the obese are less likely to have their blood pressures controlled. This is true for both urban and rural areas. The lower control rates for the obese suggests that being aware of one's condition alone does not necessarily transfer into effective control. It requires medication and proper administration of treatment.

Again, almost all medical facility variables are insignificant, with only one exception: having a medical facility within a community in urban areas increases the probability of successful control of hypertension for people living in the community.

\subsection{Uncontrolled Hypertension}

As mentioned earlier, the harmful effects of hypertension can be contained only if blood pressure is under control. Therefore, although prevalence of hypertension is a measure of whether a person is at risk for cardiovascular disease, what matters is whether or not the condition is ultimately controlled. Having studied factors contributing to treatment and control, conditional on 
awareness, we now turn to the outcome that we are ultimately interested in, uncontrolled hypertension. It is also the outcome measuring the overall suffering from hypertension. Different from the one defined in the previous section, this variable is defined among the whole sample regardless of their hypertension condition or awareness status.

Table 6 presents the estimation results. Older people are more likely to have uncontrolled hypertension and the age effect is similar in both urban and rural areas. Each year, a person's likelihood of having uncontrolled hypertension increases by about 1.0 percentage points (or 3.4 percent). Men are more likely to suffer than women: urban men are 4.9 percentage points (15.7 percent) more likely to have uncontrolled hypertension than urban women, and rural men are 3.3 percentage points (or12.4 percent) more likely than rural women.

After controlling for socioeconomic status and behaviour risks, rural men are still 4.6 percentage points (or 17.3 percent) more likely to suffer from hypertension than rural women, compared to a 4.2 percentage point (or 13.3 percent) difference in urban areas. It is interesting to note that after controlling for health behaviours, the gender difference becomes significantly larger in the rural sample, jumping from 3.3 percentage points to 4.6 percentage points, while the effects decrease in the urban sample from 4.9 to 4.2 percentage points. This means that the gender difference in health behavior is different in the two areas (see Appendix Table 4).

Education has some effect on the final non-control of hypertension among the urban sample. This result is interesting since there is no education gradient in actual prevalence. However, educated urban residents have an advantage in each step towards successful control: awareness, conditional treatment and conditional control. Thus turning to overall suffering, the cumulative advantages become statistically significant. No significant income gradient has been found in either area.

As for the behavioural variables, being overweight, obese, or a heavy drinker still have significant positive effects on ultimate non-control. The effects of being overweight and obese are about 12.9 and 23.2 percentage points (or 40.8 and 73.4 percents) in urban areas, and 16.1 and 23.0 percentage points (or 60.5 and 86.4 percents) in rural areas. The effects of heavy drinking are also important in rural areas, but much smaller in magnitude compared to obesity. Except for the distance variable in the urban areas, all access variables are insignificant. 
Having presented results from various models, we now summarize the results across models.

1. Age. There is a large positive age gradient in the prevalence of hypertension, but a much smaller and positive age gradient in awareness, resulting in a significant age gradient in overall suffering from hypertension both in rural and urban areas.

2. Gender. Men are among the most disadvantaged group with respect to hypertension. Men have higher prevalence, lower awareness and are not more likely to have their hypertension under control. As a result, in both urban and rural areas, men end up suffering more than women.

3. Income and education. Income gradients are relatively weak compared to education. A significant education gradient exists in the awareness of hypertension although no gradient is found in actual prevalence. An education gradient is also observed with treatment of hypertension in urban areas; however, this educational advantage does not transfer to effective control. Therefore, only a small educational advantage for the highly-educated is observed in final uncontrolled hypertension. In rural areas, however, no education gradient is found in any stage of hypertension, suggesting that little useful information is available in rural areas, not even to the better educated.

4. Health behavior and access to health care. Health behavior (mostly obesity and heavy drinking) has significant effects on nearly every aspect of hypertension, while for the access variables examined, we find what matters on hypertension awareness is not distance to the nearest facility or the grade of a medical facility, but whether a doctor tests for blood pressure during a medical visit. These results suggest that the most important consideration of public policy aiming at reducing the linkage between income inequality and health inequality is to strengthen the public health care system to improve health education, and to provide better prevention, screening, treatment and effective control of chronic diseases. 


\section{Conclusions}

Many developing countries are undergoing epidemiological transitions from infectious to chronic diseases. The emergent nature of chronic diseases implies that under-diagnosis is likely to be widespread, and due to differing degrees of diagnosis and disease management by social economic class, health inequality may exacerbate social inequality. Using data from China, and using hypertension as an example, we find that the prevalence of hypertension in China is close to levels in developed countries, suggesting that China is indeed well underway in, if not close to, completing the epidemiological transition. However, under-diagnosis is pervasive, treatment is rare, and control is highly ineffective. This is strong evidence that the transition has caught China by surprise, and the country is ill-prepared to handle the challenges posed by the emergence of illnesses associated with an affluent society.

Our second major goal has been to explore SES gradients in the prevalence, awareness, control of, and suffering from chronic diseases among our study population, with SES represented by incomes and education. Our results highlight the following major points.

First, consistent with evidence from other developing countries, we do not find significant income and education gradients in the actual prevalence of hypertension, indicating that hypertension affects all socioeconomic classes. The key is in finding who is most aware of their condition, and whose condition can be treated and successfully controlled. We find that income gradients are absent or weak in almost all aspects of hypertension, suggesting that prevention and control of hypertension is not constrained by income in our study population ${ }^{19}$. However, we find significant education gradients in diagnosis and treatment in urban areas but not in rural areas. Therefore, the better educated in urban areas are most capable of escaping the harm of chronic illnesses if the higher treatment percentages can be effectively translated to successful control. This suggests that in places where rapid epidemiological transition is happening, better endowed have an information advantage, and public awareness campaigns are needed to teach people how to discover hypertension and receive proper treatment and care.

Secondly, at least in China, public health care services contribute little in informing patients of their hypertension status. This indicates that the public health care system needs to

\footnotetext{
19 Since the CHNS data under sample western, poor provinces, it is likely that income constraint still exists in some parts of China.
} 
acknowledge the epidemiological transition and pay more attention to the prevention, screening, and treatment of chronic diseases. Furthermore, we find that health behavior, and obesity in particular, has large and significant effects on the prevalence of hypertension.

Overall, our results suggest that along with rapid economic growth China has already entered an era where over-nutrition and chronic illnesses have become major health issues. There is an urgent need to re-prioritize health investment and to educate the public about chronic illnesses, and to raise the quality of health care so that patients receive proper diagnosis and guidance on how to treat and control these chronic illnesses.

Additionally, the extremely low rate of awareness is a warning against using self-reporting as a reliable indicator of health conditions in countries undergoing rapid epidemiological transition. Thus measuring health conditions through health examinations is particularly important in these countries. 


\section{References:}

Barker D J P, 1997. Maternal Nutrition, Fetal Nutrition, and Disease in Later Life. Nutrition Vol. 13, No.9.

Eggleston K, Lindelow, M, L, Li, Q, Meng and Wagstaff, A. 2008. Health Service Delivery in China: A Literature Review. Health Economics 17, 149-165

Gribble J N, Preston S H, eds. 1993. The Epidemiological Transition: Policy and Planning Implications for Developing Countries. Washington: National Academy Press.

Gu D, Reynolds K, Wu X, Chen J, Duan X, Muntner P, et al. 2002. Prevalence, Awareness, Treatment, and Control of Hypertension in China. Hypertension 40, 920-927.

Hajjar I , Kotchen T A. 2003. Trends in Prevalence, Awareness, Treatment, and Control of Hypertension in the United States, 1988-2000. Journal of American Medical Association 290(22), 199-206.

He J, Whelton P K, Wu X, Burt V L, Tao S, Roccella E J, Klag M J. 1996. Comparison of Secular Trends in Prevalence of Hypertension in the People’s Republic of China and the United States of America. American Journal of Hypertension. 9:74A.

He J, Gu D F, Wu X G, Reynolds K, Duan X F, Yao C H, Wang J L, Chen C S, Chen J, Wildman R P, Klag M J, and Whelton P K. 2005. Major Causes of Death among Men and Women in China. The New England Journal of Medicine 353(11), 1124-1134.

Hou X H. 2008. Urban-Rural Disparity of Overweight, Hypertension, Undiagnosed Hypertension, and Untreated Hypertension in China. Asia-Pacific Journal of Public Health 20. 159-169.

Inoue S, Zimmet P, Caterson I, Chunming C, et al. 2002. The Asia-Pacific Perspective: Redefining Obesity and Its Treatment. Western Pacific Region, Sydney, Australia: Health Communications Australia Pty Limited.

Johnston D W, Propper C, Shields M A. 2009. Comparing Subjective and Objective Measures of Health: Evidence from Hypertension for the Income/Health Gradient. Journal of Health Economics 28(3), 540-552

Liu G G, Dow W H, Fu A Z, Akin J and Lance P, 2008. Income productivity in China: On the role of Health. Journal of Health Economics 27, 27-44.

Moser M and Setaro JF, 2006. Resistant or Difficult-to-Control Hypertension. The New England Journal of Medicine 355:4, July 27 
National Heart, Lung, and Blood Institute. 1997. The Sixth Report of the Joint National Committee on the Prevention, Detection, Evaluation and Treatment of High Blood Pressure. NIH Publication 98-04080. (JNC 6).

----. 2004. The Seventh Report of the Joint National Committee on the Prevention, Detection, Evaluation and Treatment of High Blood Pressure. NIH Publication 98-045230. (JNC 7).

Popkin B M, Keyou G, Zhai F, Guo X, Zohoori N. 1993. The Nutrition Transition in China: A Cross-Sectional Analysis. European Journal of Clinical Nutrition 47, 333-46.

Primatesta P, Brookes M, Poulter N R. 2001. Improved Hypertension Management and Control, Result From the Health Survey for England 1998. Hypertension 38. 827.

Smith J P. 2007. Diabetes and the Rise of the SES Health Gradient. NBER Working Paper 12905.

Wagstaff, A, M. Lindelow, S. Wang, S. Zhang. 2003. Reforming China Rural Health System. The World Bank.

WHO. 2009. WHO Global database on body mass index. http://www.who.int/infobase.

Witoelar, F, J Strauss and B Sikoki, 2009. "Socioeconomic Success and Health in Later Life: Evidence from the Indonesia Family Life Survey,” working paper, RAND. 
Figure 1: Diagnosed Prevalence, Actual Prevalence and Uncontrolled Rate of Hypertension

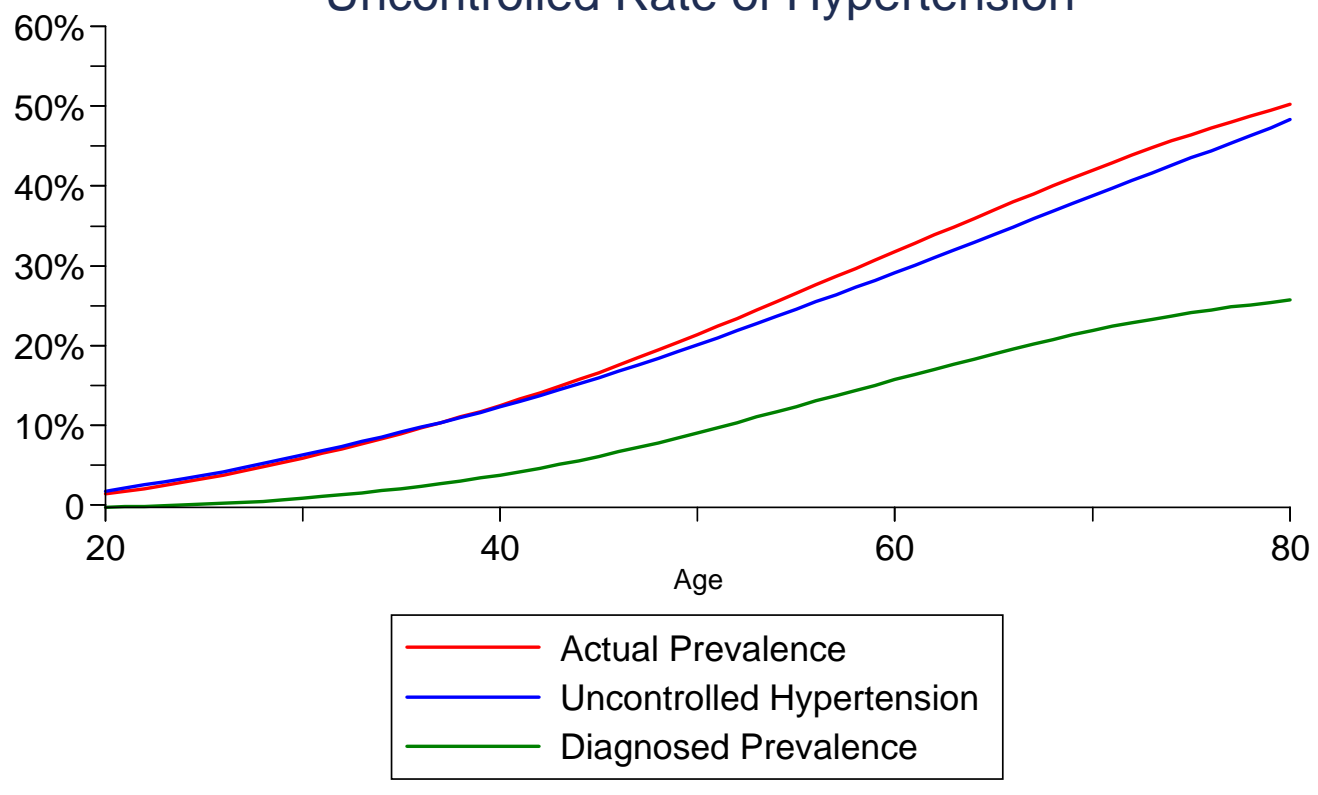

Source: CHNS, 2004 and 2006

Lowess smoothing, $\mathrm{bw}=0.8$

Figure 2: Awareness and

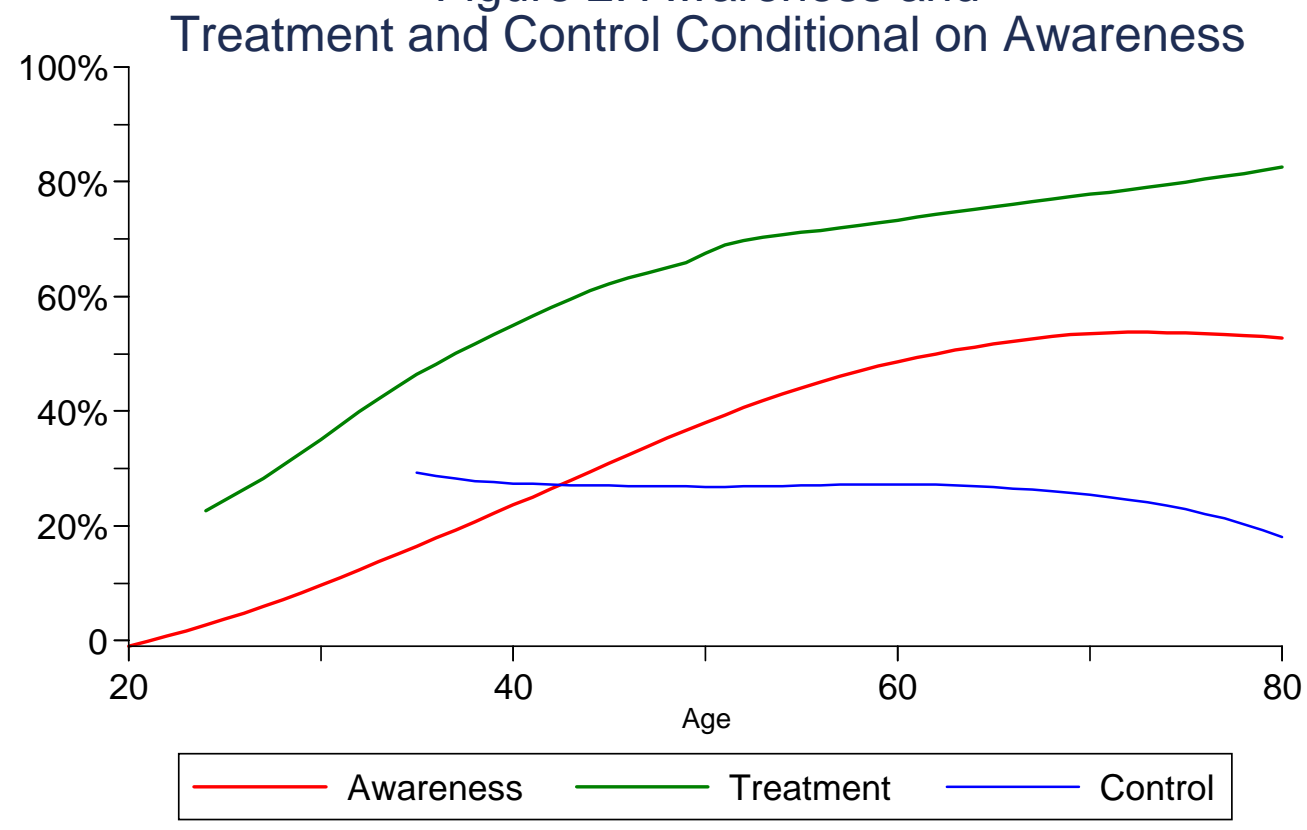

Source: CHNS, 2004 and 2006 Lowess smoothing,bw $=0.8$ 
Table 1 Descriptive Statistics of Variables

\begin{tabular}{|c|c|c|c|c|c|}
\hline \multirow[b]{2}{*}{ Variables } & \multirow[b]{2}{*}{ Total } & \multicolumn{2}{|c|}{ By Residency } & \multicolumn{2}{|l|}{ By Gender } \\
\hline & & Urban & Rural & Male & Female \\
\hline \multirow[t]{2}{*}{ Age } & 58.466 & 59.136 & $57.772 * * *$ & 58.435 & 58.495 \\
\hline & [8.995] & [9.334] & [8.575] & [8.922] & [9.061] \\
\hline \multirow[t]{2}{*}{ Male } & 0.474 & 0.467 & 0.482 & 1.000 & 0.000 \\
\hline & [0.499] & [0.499] & {$[0.500]$} & {$[0.000]$} & {$[0.000]$} \\
\hline \multirow[t]{2}{*}{ Urban } & 0.509 & 1.000 & 0.000 & 0.502 & 0.516 \\
\hline & {$[0.500]$} & {$[0.000]$} & {$[0.000]$} & {$[0.500]$} & {$[0.500]$} \\
\hline \multirow[t]{2}{*}{ Years of Schooling } & 6.165 & 7.340 & $4.946 * * *$ & 7.571 & $4.897 * * *$ \\
\hline & [4.427] & [4.634] & [3.840] & [4.017] & [4.397] \\
\hline \multirow[t]{2}{*}{ Illiterate } & 0.202 & 0.154 & $0.252^{* * *}$ & 0.078 & $0.315^{* * *}$ \\
\hline & {$[0.402]$} & {$[0.361]$} & {$[0.434]$} & {$[0.268]$} & {$[0.464]$} \\
\hline \multirow[t]{2}{*}{ Primary School } & 0.369 & 0.300 & $0.441^{* * *}$ & 0.373 & 0.366 \\
\hline & [0.483] & {$[0.458]$} & [0.497] & {$[0.484]$} & {$[0.482]$} \\
\hline \multirow[t]{2}{*}{ Junior High School } & 0.222 & 0.234 & $0.209 * * *$ & 0.285 & $0.165^{* * *}$ \\
\hline & {$[0.415]$} & {$[0.423]$} & {$[0.407]$} & {$[0.451]$} & {$[0.371]$} \\
\hline \multirow[t]{2}{*}{ Senior High School and Above } & 0.205 & 0.310 & $0.095^{* * *}$ & 0.262 & $0.153^{* * *}$ \\
\hline & {$[0.404]$} & {$[0.463]$} & {$[0.294]$} & {$[0.440]$} & {$[0.360]$} \\
\hline \multirow[t]{2}{*}{ Missing_Years of Schooling } & 0.002 & 0.002 & 0.003 & 0.002 & 0.002 \\
\hline & {$[0.048]$} & {$[0.044]$} & {$[0.052]$} & {$[0.048]$} & {$[0.048]$} \\
\hline \multirow[t]{2}{*}{ Household Income Per Capita (yuan/year) } & 7008.911 & 9079.186 & $4869.685^{* * *}$ & 7148.128 & 6883.302 \\
\hline & [8682.681] & [10236.001] & [6002.657] & [8765.752] & [8605.958] \\
\hline \multirow[t]{2}{*}{ Missing_Household Income } & 0.012 & 0.014 & $0.009 * *$ & 0.012 & 0.011 \\
\hline & {$[0.107]$} & [0.117] & {$[0.096]$} & [0.107] & [0.107] \\
\hline \multirow[t]{2}{*}{ Married } & 0.859 & 0.853 & $0.866^{*}$ & 0.910 & $0.813^{* * *}$ \\
\hline & {$[0.348]$} & [0.354] & {$[0.341]$} & {$[0.286]$} & {$[0.390]$} \\
\hline \multirow[t]{2}{*}{ Minority } & 0.125 & 0.093 & $0.158^{* * *}$ & 0.131 & $0.120^{*}$ \\
\hline & {$[0.331]$} & {$[0.291]$} & {$[0.365]$} & [0.338] & [0.324] \\
\hline Missing_Minority & 0.091 & 0.110 & $0.071^{* * *}$ & 0.064 & $0.115^{* * *}$ \\
\hline & {$[0.287]$} & [0.313] & {$[0.256]$} & {$[0.244]$} & [0.319] \\
\hline Smoking Quitter & 0.052 & 0.059 & $0.044^{* * *}$ & 0.104 & $0.005^{* * *}$ \\
\hline & {$[0.222]$} & {$[0.236]$} & {$[0.205]$} & [0.305] & {$[0.073]$} \\
\hline Current Smoker & 0.288 & 0.261 & $0.316^{* * *}$ & 0.549 & $0.053^{* * *}$ \\
\hline & {$[0.453]$} & [0.439] & {$[0.465]$} & {$[0.498]$} & {$[0.225]$} \\
\hline Missing_Ever Smoking & 0.002 & 0.002 & 0.002 & 0.003 & $0.000 * * *$ \\
\hline & {$[0.040]$} & {$[0.040]$} & [0.040] & {$[0.054]$} & {$[0.020]$} \\
\hline 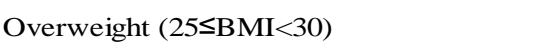 & 0.258 & 0.307 & $0.208^{* * *}$ & 0.237 & $0.277 * * *$ \\
\hline & {$[0.438]$} & {$[0.461]$} & {$[0.406]$} & {$[0.425]$} & {$[0.448]$} \\
\hline Obesity (BMI $\geq 30)$ & 0.049 & 0.059 & $0.039 * * *$ & 0.036 & $0.061 * * *$ \\
\hline & {$[0.216]$} & {$[0.235]$} & [0.193] & {$[0.186]$} & {$[0.239]$} \\
\hline Heavy Drinking & 0.174 & 0.160 & $0.188^{* * *}$ & 0.336 & $0.027 * * *$ \\
\hline & [0.379] & {$[0.366]$} & {$[0.391]$} & {$[0.472]$} & {$[0.162]$} \\
\hline Missing_Heavy Drinking & 0.008 & 0.009 & 0.007 & 0.013 & $0.003^{* * *}$ \\
\hline & [0.089] & [0.096] & [0.081] & {$[0.113]$} & [0.059] \\
\hline Having Medical Insurance & 0.412 & 0.485 & $0.337 * * *$ & 0.440 & $0.387 * * *$ \\
\hline & [0.492] & {$[0.500]$} & {$[0.473]$} & {$[0.496]$} & {$[0.487]$} \\
\hline Missing_Having Medical Insurance & 0.003 & 0.004 & $0.002 *$ & 0.003 & 0.003 \\
\hline & {$[0.051]$} & {$[0.060]$} & [0.040] & {$[0.050]$} & [0.052] \\
\hline Medical Facility (Community Level) & & & & & \\
\hline The Nearest Facility is a beyond- & 0.309 & 0.337 & $0.280^{* * *}$ & 0.304 & 0.312 \\
\hline county Level Hospital & {$[0.462]$} & {$[0.473]$} & {$[0.449]$} & {$[0.460]$} & {$[0.464]$} \\
\hline The Nearest Medical Facility & 0.685 & 0.638 & $0.734^{* * *}$ & 0.684 & 0.686 \\
\hline is within Community & {$[0.465]$} & {$[0.481]$} & {$[0.442]$} & {$[0.465]$} & {$[0.464]$} \\
\hline Distance $(\mathrm{Km})$ to the Nearest & 0.191 & 0.216 & $0.165^{* * *}$ & 0.193 & 0.190 \\
\hline Medical Facility & [0.499] & {$[0.471]$} & {$[0.526]$} & [0.505] & [0.494] \\
\hline Missing_Distance & 0.158 & 0.148 & $0.168^{* * *}$ & 0.158 & 0.158 \\
\hline & [0.365] & {$[0.356]$} & {$[0.374]$} & [0.365] & [0.365] \\
\hline Observations & 9944 & 5065 & 4879 & 4717 & 5227 \\
\hline
\end{tabular}

Source: CHNS, 2004 and 2006, age 45-80

Note: 1 . * significant at $10 \%$; ** significant at $5 \%$; *** significant at $1 \%$

2. Standard Deviations in Brackets. 
Table 2 Prevalence, Awareness, Control and Suffering of Hypertension by Residency, Gender

\begin{tabular}{|c|c|c|c|c|c|c|}
\hline Residen & $\begin{array}{c}\text { Diagnosed } \\
\text { Hypertension }^{\mathrm{a}} \\
\end{array}$ & $\begin{array}{c}\text { Actual } \\
\text { Prevalence }^{\mathrm{b}}\end{array}$ & Uncontrolled Rate $^{c}$ & Awareness $^{\mathrm{d}}$ & $\begin{array}{c}\text { Treatment }{ }^{\mathrm{e}} \text { among Diagnosed } \\
\text { Hypertensive Patients }\end{array}$ & $\begin{array}{c}\text { Control }{ }^{\mathrm{f}} \text { among Diagnosed } \\
\text { Hypertensive Patients }\end{array}$ \\
\hline & 1 & 2 & 3 & 4 & 5 & 6 \\
\hline \multicolumn{7}{|c|}{ Panel A: All } \\
\hline Total & 0.124 & 0.327 & 0.291 & 0.379 & 0.770 & 0.110 \\
\hline Urban & 0.170 & 0.368 & 0.316 & 0.462 & 0.807 & 0.140 \\
\hline Rural & $0.077^{*}$ & $0.285^{*}$ & $0.266^{*}$ & $0.268 *$ & $0.685^{*}$ & $0.069 *$ \\
\hline Male & 0.110 & 0.340 & 0.307 & 0.325 & 0.737 & 0.098 \\
\hline Female & $0.136^{\circ \circ}$ & $0.315^{\circ \circ}$ & $0.277^{\circ \circ}$ & $0.432^{\circ \circ}$ & $0.794^{\circ}$ & $0.121^{\circ}$ \\
\hline \multicolumn{7}{|c|}{ Panel B: Male } \\
\hline Urban & 0.156 & 0.383 & 0.334 & 0.407 & 0.751 & 0.127 \\
\hline Rural & $0.065^{*}$ & $0.298 *$ & $0.280 *$ & $0.219 *$ & $0.706^{*}$ & $0.060 *$ \\
\hline \multicolumn{7}{|c|}{ Panel C: Female } \\
\hline Urban & 0.182 & 0.355 & 0.301 & 0.514 & 0.849 & 0.152 \\
\hline Rural & $0.087^{*}$ & $0.274^{*}$ & $0.252^{*}$ & $0.318^{*}$ & $0.671^{*}$ & $0.078^{*}$ \\
\hline
\end{tabular}

Source: CHNS, 2004 and 2006, age 45-80.

Note:

a. Self-Reports: Defined as self-reporting to have been diagnosed by a doctor.

b. Actual Prevalence: Defined as clinically diagnosed hypertensive (systolic blood pressure $\geq 140 \mathrm{~mm} \mathrm{Hg}$, or diastolic blood pressure $\geq 90 \mathrm{~mm} \mathrm{Hg}$ ) plus with normal blood pressure readings but taking anti-hypertensive medication at the time.

c. Uncontrolled Rate: Defined as having hypertension readings irrespective of awareness or treatment.

d. Awareness: Defined as being hypertensive and self-reporting to have been diagnosed by a doctor.

e. Treatment: Defined as being aware of hypertension and and is receiving anti-hypertensive medications.

f. Control: Defined as being aware of hypertension and having blood pressure under control.

*: Rural mean significantly different from urban at $1 \%$.

$\circ, \circ$ : Female mean significantly different from men at $1 \%$ and $5 \%$, respectively. 
Table 3 Probit Model of Actual Hypertension Prevalence

\begin{tabular}{|c|c|c|c|c|}
\hline \multirow{3}{*}{ Variables } & \multicolumn{4}{|c|}{ Actual Prevalence } \\
\hline & \multicolumn{2}{|l|}{ Urban } & \multicolumn{2}{|l|}{ Rural } \\
\hline & 5 & 6 & 7 & 8 \\
\hline \multirow[t]{2}{*}{ Age } & $0.012 * * *$ & $0.012 * * *$ & $0.011^{* * *}$ & $0.011^{* * *}$ \\
\hline & {$[0.001]$} & {$[0.001]$} & {$[0.001]$} & {$[0.001]$} \\
\hline \multirow[t]{2}{*}{ Male } & $0.040^{* * *}$ & 0.025 & $0.031 * *$ & $0.046 * * *$ \\
\hline & {$[0.014]$} & [0.017] & {$[0.014]$} & [0.017] \\
\hline \multirow[t]{2}{*}{ Married } & 0.015 & 0.011 & -0.005 & -0.008 \\
\hline & {$[0.020]$} & [0.019] & {$[0.020]$} & {$[0.020]$} \\
\hline \multirow[t]{2}{*}{ Minority } & 0.002 & 0.014 & $0.038 *$ & 0.034 \\
\hline & {$[0.027]$} & {$[0.027]$} & {$[0.023]$} & {$[0.023]$} \\
\hline \multicolumn{5}{|l|}{ Education Categories } \\
\hline \multirow[t]{2}{*}{ Primary School } & -0.001 & -0.002 & -0.009 & -0.012 \\
\hline & {$[0.021]$} & {$[0.021]$} & {$[0.018]$} & [0.017] \\
\hline \multirow[t]{2}{*}{ Junior High School } & -0.002 & -0.005 & -0.023 & -0.029 \\
\hline & {$[0.024]$} & {$[0.024]$} & {$[0.022]$} & {$[0.021]$} \\
\hline \multirow[t]{2}{*}{ Senior High School and Above } & -0.031 & -0.025 & -0.032 & -0.036 \\
\hline & {$[0.024]$} & {$[0.025]$} & [0.027] & {$[0.027]$} \\
\hline \multicolumn{5}{|l|}{ Income Categories } \\
\hline \multirow[t]{2}{*}{ The 2nd Quartile } & 0.015 & 0.006 & 0.002 & -0.000 \\
\hline & [0.019] & [0.019] & [0.018] & [0.017] \\
\hline \multirow[t]{2}{*}{ The 3rd Quartile } & -0.001 & -0.022 & -0.006 & -0.007 \\
\hline & {$[0.020]$} & {$[0.020]$} & {$[0.018]$} & {$[0.018]$} \\
\hline \multirow[t]{2}{*}{ The 4th Quartile } & -0.008 & -0.030 & -0.007 & -0.022 \\
\hline & {$[0.021]$} & {$[0.021]$} & [0.019] & [0.018] \\
\hline \multicolumn{5}{|l|}{ Risk Factors } \\
\hline \multirow[t]{2}{*}{ Smoking Quitter } & & $0.061 * *$ & & 0.015 \\
\hline & & {$[0.030]$} & & {$[0.032]$} \\
\hline \multirow[t]{2}{*}{ Current Smoker } & & 0.007 & & $-0.032 *$ \\
\hline & & [0.018] & & [0.017] \\
\hline \multirow[t]{2}{*}{ Overweight } & & $0.153^{* * *}$ & & $0.175^{* * *}$ \\
\hline & & {$[0.015]$} & & [0.017] \\
\hline \multirow[t]{2}{*}{ Obesity } & & $0.246^{* * *}$ & & $0.248 * * *$ \\
\hline & & {$[0.028]$} & & {$[0.035]$} \\
\hline \multirow[t]{2}{*}{ Heavy Drinker } & & $0.035 *$ & & $0.067 * * *$ \\
\hline & & {$[0.020]$} & & [0.019] \\
\hline Having Medical Insurance & & 0.017 & & 0.010 \\
\hline & & [0.015] & & [0.019] \\
\hline Medical Facility (Community Level) & & & & \\
\hline The Nearest Facility is a beyond- & & 0.012 & & $0.040^{* *}$ \\
\hline county Level Hospital & & {$[0.021]$} & & {$[0.021]$} \\
\hline The Nearest Medical Facility & & -0.013 & & -0.010 \\
\hline is within Community & & {$[0.028]$} & & [0.034] \\
\hline Distance $(\mathrm{Km})$ to the Nearest & & $-0.038 *$ & & -0.005 \\
\hline Medical Facility & & {$[0.021]$} & & [0.017] \\
\hline Year Dummy & $-0.034 * * *$ & $-0.040 * * *$ & -0.020 & $-0.034^{* *}$ \\
\hline & {$[0.013]$} & {$[0.014]$} & {$[0.012]$} & {$[0.016]$} \\
\hline County Dummies & Yes & Yes & Yes & Yes \\
\hline Observations & 5065 & 5036 & 4879 & 4861 \\
\hline Pseudo R-squared & 0.0957 & 0.1227 & 0.0761 & 0.1060 \\
\hline
\end{tabular}

Source: CHNS, 2004 and 2006, age 45-80

Note: 1 . * significant at $10 \%$; ** significant at $5 \%$; *** significant at $1 \%$.

2. Marginal effects reported. Standard errors in brackets.

3. Dummy variables indicating missing of minority, schooling, household income, smoking, drinking and distance to nearest facility are included in the regression but not reported. 
Table 4 Probit Model of Conditional Hypertension Awareness (Dependent Variable: Aware of Condition $=1$; 0 otherwise)

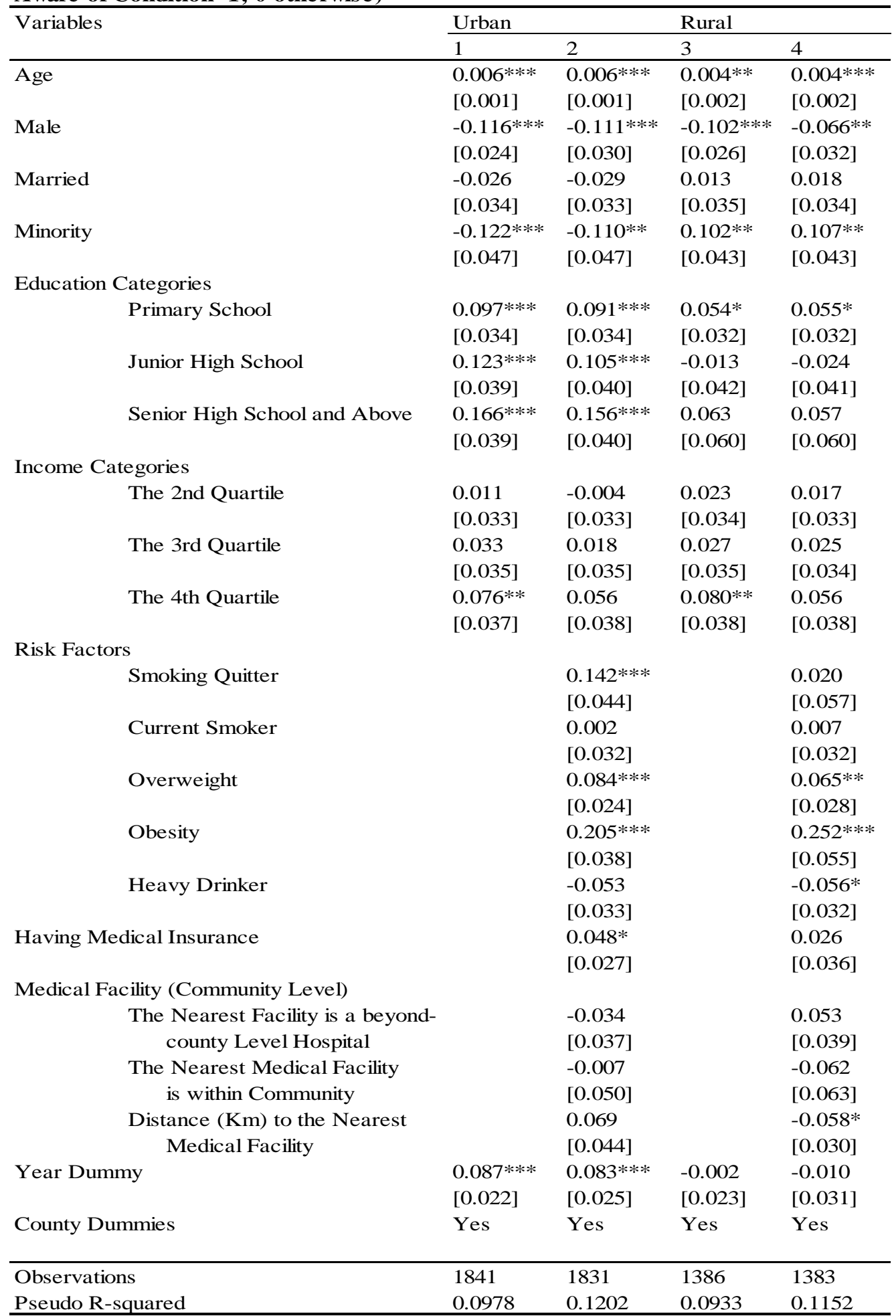

Source: CHNS, 2004 and 2006, age 45-80

Note: $1 . *$ significant at $10 \%$; ** significant at $5 \%$; *** significant at $1 \%$.

2. Marginal effects reported. Standard errors in brackets.

3. Dummy variables indicating missing of minority, schooling, household income, smoking, drinking and distance to nearest facility are included in the regression but not reported. 
Table 4-1 Probit Model of the Role of Medical Services on Hypertension Awareness (Dependent Variable: Aware=1; 0 otherwise)

\begin{tabular}{|c|c|c|}
\hline & Urban & Rural \\
\hline \multirow[t]{2}{*}{ Age } & $0.005^{* * *}$ & $0.004^{* * *}$ \\
\hline & {$[0.001]$} & {$[0.001]$} \\
\hline \multirow[t]{2}{*}{ Male } & $-0.102 * * *$ & $-0.084 * * *$ \\
\hline & {$[0.025]$} & {$[0.025]$} \\
\hline \multirow[t]{2}{*}{ Married } & -0.014 & -0.013 \\
\hline & {$[0.028]$} & {$[0.028]$} \\
\hline \multirow{2}{*}{ Minority } & -0.041 & 0.042 \\
\hline & [0.035] & [0.035] \\
\hline \multicolumn{3}{|l|}{ Education Categories } \\
\hline \multirow[t]{2}{*}{ Primary School } & $0.087 * * *$ & $0.073 * * *$ \\
\hline & {$[0.027]$} & {$[0.026]$} \\
\hline \multirow[t]{2}{*}{ Junior High School } & $0.091 * * *$ & 0.033 \\
\hline & {$[0.033]$} & [0.033] \\
\hline \multirow[t]{2}{*}{ Senior High School and Above } & $0.166^{* * *}$ & $0.129 * * *$ \\
\hline & {$[0.033]$} & {$[0.037]$} \\
\hline \multicolumn{3}{|l|}{ Income Categories } \\
\hline \multirow[t]{2}{*}{ The 2nd Quartile } & -0.017 & -0.005 \\
\hline & {$[0.026]$} & {$[0.027]$} \\
\hline \multirow[t]{2}{*}{ The 3rd Quartile } & 0.002 & 0.022 \\
\hline & {$[0.027]$} & {$[0.027]$} \\
\hline \multirow[t]{2}{*}{ The 4th Quartile } & 0.036 & 0.030 \\
\hline & {$[0.030]$} & {$[0.030]$} \\
\hline \multicolumn{3}{|l|}{ Risk Factors } \\
\hline \multirow[t]{2}{*}{ Smoking Quitter } & $0.101 * * *$ & $0.078 *$ \\
\hline & {$[0.038]$} & {$[0.042]$} \\
\hline \multirow[t]{2}{*}{ Current Smoker } & 0.025 & 0.012 \\
\hline & {$[0.026]$} & {$[0.026]$} \\
\hline \multirow{2}{*}{ Overweight } & $0.085 * * *$ & $0.085 * * *$ \\
\hline & {$[0.020]$} & {$[0.021]$} \\
\hline \multirow[t]{2}{*}{ Obesity } & $0.222 * * *$ & $0.240 * * *$ \\
\hline & [0.033] & {$[0.037]$} \\
\hline \multirow[t]{2}{*}{ Heavy Drinker } & $-0.050 *$ & -0.042 \\
\hline & {$[0.027]$} & {$[0.027]$} \\
\hline \multirow[t]{2}{*}{ Having Medical Insurance } & $0.042 *$ & 0.022 \\
\hline & [0.022] & [0.025] \\
\hline \multirow[t]{2}{*}{ In-patients } & $0.279 * * *$ & $0.266 * * *$ \\
\hline & {$[0.062]$} & {$[0.080]$} \\
\hline \multirow[t]{2}{*}{ Out-patients } & $0.235 * * *$ & $0.210^{* * *}$ \\
\hline & {$[0.024]$} & {$[0.025]$} \\
\hline \multirow[t]{2}{*}{ Year Dummy } & $0.047^{* *}$ & $0.023 * *$ \\
\hline & [0.019] & {$[0.024]$} \\
\hline County Dummies & Yes & Yes \\
\hline Observations & 2522 & 2273 \\
\hline Log-Likelihood & 0.1459 & 0.1695 \\
\hline
\end{tabular}

Source: CHNS, 2004 and 2006, age 45-80

Note: 1 . * significant at $10 \%$; ** significant at 5\%; *** significant at $1 \%$.

2. Marginal effects reported. Standard errors in brackets.

3. Dummy variables indicating missing of minority, schooling, household income, smoking and drinking are included in the regression but not reported. 
Table 5 Probit Model of Conditional Hypertension Treatment and Control

\begin{tabular}{|c|c|c|c|c|c|c|c|c|}
\hline \multirow{3}{*}{ Variables } & \multicolumn{4}{|c|}{$\begin{array}{l}\text { Treatment among Diagnosed } \\
\text { Hypertensive Patients }\end{array}$} & \multicolumn{4}{|c|}{$\begin{array}{l}\text { Control among Diagnosed } \\
\text { Hypertensive Patients }\end{array}$} \\
\hline & \multicolumn{2}{|l|}{ Urban } & \multicolumn{2}{|l|}{ Rural } & \multicolumn{2}{|l|}{ Urban } & \multicolumn{2}{|l|}{ Rural } \\
\hline & 1 & 2 & 3 & 4 & 5 & 6 & 7 & 8 \\
\hline$\overline{\text { Age }}$ & $\begin{array}{l}0.005^{* * *} \\
{[0.002]}\end{array}$ & $\begin{array}{l}0.006 * * * \\
{[0.002]}\end{array}$ & $\begin{array}{l}0.004 \\
{[0.004]}\end{array}$ & $\begin{array}{l}0.005 \\
{[0.004]}\end{array}$ & $\begin{array}{l}0.000 \\
{[0.002]}\end{array}$ & $\begin{array}{l}0.000 \\
{[0.002]}\end{array}$ & $\begin{array}{l}-0.009 * * * \\
{[0.004]}\end{array}$ & $\begin{array}{l}-0.012^{* * *} \\
{[0.004]}\end{array}$ \\
\hline Male & $\begin{array}{l}-0.127 * * * \\
{[0.033]}\end{array}$ & $\begin{array}{l}-0.092 * * \\
{[0.044]}\end{array}$ & $\begin{array}{l}0.052 \\
{[0.056]}\end{array}$ & $\begin{array}{l}0.111^{*} \\
{[0.067]}\end{array}$ & $\begin{array}{l}0.012 \\
{[0.037]}\end{array}$ & $\begin{array}{l}-0.031 \\
{[0.048]}\end{array}$ & $\begin{array}{l}0.055 \\
{[0.060]}\end{array}$ & $\begin{array}{l}-0.016 \\
{[0.074]}\end{array}$ \\
\hline Married & $\begin{array}{l}-0.064 \\
{[0.039]}\end{array}$ & $\begin{array}{l}-0.058 \\
{[0.040]}\end{array}$ & $\begin{array}{l}-0.016 \\
{[0.076]}\end{array}$ & $\begin{array}{l}-0.036 \\
{[0.077]}\end{array}$ & $\begin{array}{l}0.033 \\
{[0.048]}\end{array}$ & $\begin{array}{l}0.028 \\
{[0.048]}\end{array}$ & $\begin{array}{l}0.093 \\
{[0.070]}\end{array}$ & $\begin{array}{l}0.081 \\
{[0.073]}\end{array}$ \\
\hline Minority & $\begin{array}{l}-0.157 * \\
{[0.085]}\end{array}$ & $\begin{array}{l}-0.177^{* *} \\
{[0.085]}\end{array}$ & $\begin{array}{l}-0.034 \\
{[0.080]}\end{array}$ & $\begin{array}{l}-0.030 \\
{[0.080]}\end{array}$ & $\begin{array}{l}-0.095 \\
{[0.074]}\end{array}$ & $\begin{array}{l}-0.065 \\
{[0.077]}\end{array}$ & $\begin{array}{l}-0.022 \\
{[0.082]}\end{array}$ & $\begin{array}{l}-0.032 \\
{[0.085]}\end{array}$ \\
\hline Education Categories & & & & & & & & \\
\hline Primary School & $\begin{array}{l}0.103^{* *} \\
{[0.041]}\end{array}$ & $\begin{array}{l}0.103^{* *} \\
{[0.041]}\end{array}$ & $\begin{array}{l}0.019 \\
{[0.065]}\end{array}$ & $\begin{array}{l}0.046 \\
{[0.065]}\end{array}$ & $\begin{array}{l}0.026 \\
{[0.055]}\end{array}$ & $\begin{array}{l}0.037 \\
{[0.055]}\end{array}$ & $\begin{array}{l}0.002 \\
{[0.067]}\end{array}$ & $\begin{array}{l}-0.009 \\
{[0.066]}\end{array}$ \\
\hline Junior High School & $\begin{array}{l}0.092 * * \\
{[0.044]}\end{array}$ & $\begin{array}{l}0.092^{* *} \\
{[0.045]}\end{array}$ & $\begin{array}{l}-0.061 \\
{[0.097]}\end{array}$ & $\begin{array}{l}-0.052 \\
{[0.097]}\end{array}$ & $\begin{array}{l}0.055 \\
{[0.065]}\end{array}$ & $\begin{array}{l}0.034 \\
{[0.065]}\end{array}$ & $\begin{array}{l}-0.098 \\
{[0.087]}\end{array}$ & $\begin{array}{l}-0.071 \\
{[0.092]}\end{array}$ \\
\hline Senior High School and Above & $\begin{array}{l}0.115^{* * *} \\
{[0.044]}\end{array}$ & $\begin{array}{l}0.119 * * \\
{[0.047]}\end{array}$ & $\begin{array}{l}0.078 \\
{[0.112]}\end{array}$ & $\begin{array}{l}0.088 \\
{[0.110]}\end{array}$ & $\begin{array}{l}0.012 \\
{[0.062]}\end{array}$ & $\begin{array}{l}-0.014 \\
{[0.064]}\end{array}$ & $\begin{array}{l}0.052 \\
{[0.130]}\end{array}$ & $\begin{array}{l}0.058 \\
{[0.130]}\end{array}$ \\
\hline Income Categories & & & & & & & & \\
\hline The 2nd Quartile & $\begin{array}{l}-0.004 \\
{[0.045]}\end{array}$ & $\begin{array}{l}-0.016 \\
{[0.046]}\end{array}$ & $\begin{array}{l}-0.055 \\
{[0.074]}\end{array}$ & $\begin{array}{l}-0.039 \\
{[0.074]}\end{array}$ & $\begin{array}{l}-0.037 \\
{[0.052]}\end{array}$ & $\begin{array}{l}-0.046 \\
{[0.052]}\end{array}$ & $\begin{array}{l}0.138^{*} \\
{[0.082]}\end{array}$ & $\begin{array}{l}0.128 \\
{[0.081]}\end{array}$ \\
\hline The 3rd Quartile & $\begin{array}{l}0.062 \\
{[0.042]}\end{array}$ & $\begin{array}{l}0.055 \\
{[0.043]}\end{array}$ & $\begin{array}{l}-0.146^{*} \\
{[0.080]}\end{array}$ & $\begin{array}{l}-0.137 * \\
{[0.079]}\end{array}$ & $\begin{array}{l}0.041 \\
{[0.054]}\end{array}$ & $\begin{array}{l}0.023 \\
{[0.055]}\end{array}$ & $\begin{array}{l}0.156^{*} \\
{[0.083]}\end{array}$ & $\begin{array}{l}0.146^{*} \\
{[0.082]}\end{array}$ \\
\hline The 4th Quartile & $\begin{array}{l}0.071 \\
{[0.043]}\end{array}$ & $\begin{array}{l}0.066 \\
{[0.045]}\end{array}$ & $\begin{array}{l}0.065 \\
{[0.073]}\end{array}$ & $\begin{array}{l}0.110 \\
{[0.075]}\end{array}$ & $\begin{array}{l}0.003 \\
{[0.055]}\end{array}$ & $\begin{array}{l}-0.021 \\
{[0.056]}\end{array}$ & $\begin{array}{l}0.025 \\
{[0.079]}\end{array}$ & $\begin{array}{l}0.019 \\
{[0.082]}\end{array}$ \\
\hline Risk Factors & & & & & & & & \\
\hline Smoking Quitter & & $\begin{array}{l}-0.023 \\
{[0.054]}\end{array}$ & & $\begin{array}{l}-0.151 \\
{[0.139]}\end{array}$ & & $\begin{array}{l}0.062 \\
{[0.064]}\end{array}$ & & $\begin{array}{l}-0.093 \\
{[0.124]}\end{array}$ \\
\hline Current Smoker & & $\begin{array}{l}0.006 \\
{[0.043]}\end{array}$ & & $\begin{array}{l}-0.020 \\
{[0.074]}\end{array}$ & & $\begin{array}{l}-0.027 \\
{[0.050]}\end{array}$ & & $\begin{array}{l}-0.041 \\
{[0.072]}\end{array}$ \\
\hline Overweight & & $\begin{array}{l}0.073^{* *} \\
{[0.031]}\end{array}$ & & $\begin{array}{l}-0.054 \\
{[0.058]}\end{array}$ & & $\begin{array}{l}-0.041 \\
{[0.036]}\end{array}$ & & $\begin{array}{l}-0.113^{* *} \\
{[0.056]}\end{array}$ \\
\hline Obesity & & $\begin{array}{l}0.124^{* * *} \\
{[0.036]}\end{array}$ & & $\begin{array}{l}-0.021 \\
{[0.083]}\end{array}$ & & $\begin{array}{l}-0.170^{* * *} \\
{[0.045]}\end{array}$ & & $\begin{array}{l}-0.191 * * * \\
{[0.062]}\end{array}$ \\
\hline Heavy Drinker & & $\begin{array}{l}-0.088^{*} \\
{[0.051]}\end{array}$ & & $\begin{array}{l}-0.164 * \\
{[0.084]}\end{array}$ & & $\begin{array}{l}0.073 \\
{[0.054]}\end{array}$ & & $\begin{array}{l}0.224 * * * \\
{[0.085]}\end{array}$ \\
\hline Having Medical Insurance & & $\begin{array}{l}0.001 \\
{[0.036]}\end{array}$ & & $\begin{array}{l}0.038 \\
{[0.074]}\end{array}$ & & $\begin{array}{l}0.082^{* *} \\
{[0.041]}\end{array}$ & & $\begin{array}{l}0.026 \\
{[0.075]}\end{array}$ \\
\hline Medical Facility (Community Level) & & & & & & & & \\
\hline $\begin{array}{l}\text { The Nearest Facility is a beyond- } \\
\text { county Level Hospital }\end{array}$ & & $\begin{array}{l}0.058 \\
{[0.043]}\end{array}$ & & $\begin{array}{l}0.053 \\
{[0.071]}\end{array}$ & & $\begin{array}{l}0.060 \\
{[0.053]}\end{array}$ & & $\begin{array}{l}0.031 \\
{[0.080]}\end{array}$ \\
\hline $\begin{array}{l}\text { The Nearest Medical Facility } \\
\text { is within Community }\end{array}$ & & $\begin{array}{l}-0.017 \\
{[0.060]}\end{array}$ & & $\begin{array}{l}0.154 \\
{[0.134]}\end{array}$ & & $\begin{array}{l}0.114^{*} \\
{[0.064]}\end{array}$ & & $\begin{array}{l}0.121 \\
{[0.123]}\end{array}$ \\
\hline $\begin{array}{l}\text { Distance }(\mathrm{Km}) \text { to the Nearest } \\
\text { Medical Facility }\end{array}$ & & $\begin{array}{l}-0.072 \\
{[0.051]}\end{array}$ & & $\begin{array}{l}0.101 \\
{[0.070]}\end{array}$ & & $\begin{array}{l}0.080 \\
{[0.056]}\end{array}$ & & $\begin{array}{l}-0.023 \\
{[0.085]}\end{array}$ \\
\hline Year Dummy & $\begin{array}{l}0.009 \\
{[0.029]}\end{array}$ & $\begin{array}{l}0.033 \\
{[0.033]}\end{array}$ & $\begin{array}{l}0.031 \\
{[0.048]}\end{array}$ & $\begin{array}{l}0.007 \\
{[0.068]}\end{array}$ & $\begin{array}{l}-0.041 \\
{[0.033]}\end{array}$ & $\begin{array}{l}-0.058 \\
{[0.038]}\end{array}$ & $\begin{array}{l}-0.030 \\
{[0.049]}\end{array}$ & $\begin{array}{l}-0.001 \\
{[0.069]}\end{array}$ \\
\hline County Dummies & Yes & Yes & Yes & Yes & Yes & Yes & Yes & Yes \\
\hline Observations & 762 & 760 & 360 & 358 & 786 & 784 & 337 & 332 \\
\hline Pseudo R-squared & 0.1119 & 0.1366 & 0.1260 & 0.1538 & 0.0663 & 0.0951 & 0.1056 & 0.1497 \\
\hline
\end{tabular}

Source: CHNS, 2004 and 2006, age 45-80

Note: $1 .{ }^{*}$ significant at $10 \%$; $* *$ significant at $5 \%$; *** significant at $1 \%$.

2. Marginal effects reported. Standard errors in brackets.

3. Dummy variables indicating missing of minority, schooling, household income, smoking, drinking and distance to nearest facility are included in the regression but not reported. 
Table 6 Probit Model of Uncontrolled Hypertension (Dependent Variable: SBP $\geq$ 140 or $D B P \geq 90=1$; 0 otherwise)

\begin{tabular}{|c|c|c|c|c|c|}
\hline \multirow[t]{2}{*}{ Variables } & & \multicolumn{2}{|l|}{ Urban } & \multicolumn{2}{|l|}{ Rural } \\
\hline & & 1 & 2 & 3 & 4 \\
\hline \multirow{2}{*}{\multicolumn{2}{|c|}{ Age }} & $0.009 * * *$ & $0.010^{* * *}$ & $0.010^{* * *}$ & $0.011^{* * *}$ \\
\hline & & {$[0.001]$} & {$[0.001]$} & {$[0.001]$} & {$[0.001]$} \\
\hline \multirow{2}{*}{\multicolumn{2}{|c|}{ Male }} & $0.049 * * *$ & $0.042^{* *}$ & $0.033 * *$ & $0.046^{* * *}$ \\
\hline & & {$[0.013]$} & {$[0.017]$} & {$[0.014]$} & {$[0.017]$} \\
\hline \multirow{2}{*}{\multicolumn{2}{|c|}{ Married }} & 0.012 & 0.007 & -0.011 & -0.013 \\
\hline & & [0.019] & [0.019] & [0.019] & [0.019] \\
\hline \multirow{2}{*}{\multicolumn{2}{|c|}{ Minority }} & 0.024 & 0.033 & 0.030 & 0.025 \\
\hline & & [0.027] & [0.027] & [0.022] & {$[0.022]$} \\
\hline \multicolumn{6}{|c|}{ Education Categories } \\
\hline \multirow{2}{*}{\multicolumn{2}{|c|}{ Primary School }} & -0.016 & -0.017 & -0.014 & -0.017 \\
\hline & & {$[0.020]$} & {$[0.020]$} & {$[0.017]$} & {$[0.017]$} \\
\hline \multirow{2}{*}{\multicolumn{2}{|c|}{ Junior High School }} & -0.022 & -0.021 & -0.014 & -0.019 \\
\hline & & {$[0.023]$} & [0.023] & {$[0.022]$} & {$[0.021]$} \\
\hline \multirow{2}{*}{\multicolumn{2}{|c|}{ Senior High School and Above }} & $-0.050 * *$ & $-0.041^{*}$ & -0.036 & -0.039 \\
\hline & & {$[0.023]$} & {$[0.024]$} & {$[0.026]$} & {$[0.026]$} \\
\hline \multicolumn{6}{|c|}{ Income Categories } \\
\hline \multirow{2}{*}{\multicolumn{2}{|c|}{ The 2nd Quartile }} & 0.017 & 0.009 & -0.007 & -0.009 \\
\hline & & {$[0.018]$} & {$[0.018]$} & {$[0.017]$} & {$[0.017]$} \\
\hline \multirow{2}{*}{\multicolumn{2}{|c|}{ The 3rd Quartile }} & -0.014 & -0.028 & -0.017 & -0.019 \\
\hline & & [0.019] & [0.019] & {$[0.017]$} & {$[0.017]$} \\
\hline \multirow{2}{*}{\multicolumn{2}{|c|}{ The 4th Quartile }} & -0.017 & -0.030 & -0.014 & -0.028 \\
\hline & & {$[0.021]$} & {$[0.021]$} & {$[0.018]$} & {$[0.018]$} \\
\hline \multicolumn{6}{|c|}{ Risk Factors } \\
\hline \multirow{2}{*}{\multicolumn{2}{|c|}{ Smoking Quitter }} & & 0.015 & & 0.025 \\
\hline & & & [0.028] & & {$[0.032]$} \\
\hline \multirow{2}{*}{\multicolumn{2}{|c|}{ Current Smoker }} & & 0.008 & & -0.026 \\
\hline & & & [0.018] & & {$[0.017]$} \\
\hline \multirow{2}{*}{\multicolumn{2}{|c|}{ Overweight }} & & $0.129 * * *$ & & $0.161^{* * *}$ \\
\hline & & & {$[0.014]$} & & {$[0.017]$} \\
\hline \multirow{2}{*}{\multicolumn{2}{|c|}{ Obesity }} & & $0.232 * * *$ & & $0.230 * * *$ \\
\hline & & & {$[0.029]$} & & {$[0.035]$} \\
\hline \multirow{2}{*}{\multicolumn{2}{|c|}{ Heavy Drinker }} & & 0.025 & & $0.057 * * *$ \\
\hline & & & [0.019] & & {$[0.018]$} \\
\hline \multirow{2}{*}{\multicolumn{2}{|c|}{ Having Medical Insurance }} & & -0.005 & & 0.007 \\
\hline & & & [0.015] & & [0.018] \\
\hline Medical F & cility (Community Level) & & & & \\
\hline & The Nearest Facility is a beyond- & & 0.011 & & 0.032 \\
\hline & county Level Hospital & & {$[0.021]$} & & {$[0.020]$} \\
\hline & The Nearest Medical Facility & & -0.026 & & -0.018 \\
\hline & is within Community & & [0.027] & & {$[0.033]$} \\
\hline & Distance $(\mathrm{Km})$ to the Nearest & & $-0.051^{* *}$ & & -0.005 \\
\hline & Medical Facility & & {$[0.021]$} & & {$[0.017]$} \\
\hline Year Dun & & $-0.031 * *$ & $-0.033^{* *}$ & -0.018 & $-0.030 *$ \\
\hline & & {$[0.013]$} & {$[0.014]$} & {$[0.012]$} & {$[0.016]$} \\
\hline County D & mmies & Yes & Yes & Yes & Yes \\
\hline Observati & & 5065 & 5036 & 4879 & 4861 \\
\hline Pseudo R & quared & 0.0870 & 0.1096 & 0.0757 & 0.1022 \\
\hline
\end{tabular}

Source: CHNS, 2004 and 2006, age 45-80

Note: 1. * significant at $10 \%$; ** significant at $5 \%$; *** significant at $1 \%$.

2. Marginal effects reported. Standard errors in brackets.

3. Dummy variables indicating missing of minority, schooling, household income, smoking, drinking and distance to nearest facility are included in the regression but not reported. 
Appendix Table 1: Number of Observations

\begin{tabular}{llll}
\hline Data & $\begin{array}{l}\text { Number } \\
\text { Excluded }\end{array}$ & $\begin{array}{l}\text { Number } \\
\text { Remaining }\end{array}$ \\
\hline Total & & 23917 & \\
Restricted to observations from those aged 45-80 (including aged 45 and 80) & 13180 & 10737 & \\
Exclude if Diagnosed Blood Pressure is missing & 468 & 10269 & \\
$\begin{array}{l}\text { Exclude if Patients became aware of their hypertension through the physical } \\
\text { examination in wave 2000/2004 of CHNS. }\end{array}$ & 325 & 9944 & Table 1,2,3,6 \\
Restricted to observations who are hypertensive patients & 6690 & 3254 & Table 4,4-1 \\
Restricted to observations who are aware of their condition & 2008 & 1246 & Table 5 \\
\hline
\end{tabular}




\section{Appendix Table 2: Definition of Variables}

\begin{tabular}{|c|c|}
\hline Dependent Variables & Definitions \\
\hline Diagnosed Prevalence & $\begin{array}{l}\text { 1, if they answered "yes" to the interview question "Have you ever been told by a doctor or health } \\
\text { professional that you had hypertension"; 0, otherwise. }\end{array}$ \\
\hline Actual Prevalence & $\begin{array}{l}\text { 1, if the respondent's SBP was greater than or equal to } 140 \mathrm{~mm} \mathrm{Hg} \text { or if his/her DBP was greater } \\
\text { than or equal to } 90 \mathrm{~mm} \mathrm{Hg} \text { or if he/she was taking anti-hypertensive medications; 0, otherwise. }\end{array}$ \\
\hline Hypertension Awareness & $\begin{array}{l}\text { 1, if respondent was a diagnosed hypertensive patient and he/she was a self-reported hypertensive } \\
\text { patient; } 0 \text {, otherwise. }\end{array}$ \\
\hline $\begin{array}{l}\text { Treatment among Diagnosed Hypertensive } \\
\text { Patients }\end{array}$ & $\begin{array}{l}1 \text {, if he/she was a diagnosed hypertensive patient and he/she was receiving anti-hypertensive } \\
\text { medications; } 0 \text {, otherwise. }\end{array}$ \\
\hline $\begin{array}{l}\text { Control among Diagnosed Hypertensive } \\
\text { Patients }\end{array}$ & $\begin{array}{l}\text { 1, if he/she was receiving anti-hypertensive medications and his/her average SBP was less than } 140 \\
\mathrm{~mm} \mathrm{Hg} \text { and average DBP was less than } 90 \mathrm{~mm} \mathrm{Hg} \text {. }\end{array}$ \\
\hline Uncontrolled Hypertension & $\begin{array}{l}\text { 1, if the respondent's systolic blood pressure(SBP) was greater than or equal to } 140 \mathrm{~mm} \mathrm{Hg} \text { or if } \\
\text { his/her diastolic blood pressure(DBP) was greater than or equal to } 90 \mathrm{~mm} \mathrm{Hg} \text {; } \text {, otherwise. }\end{array}$ \\
\hline \multicolumn{2}{|r|}{ 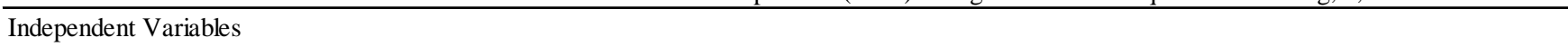 } \\
\hline Age & years of age \\
\hline Male & 1 , if male; 0 , otherwise. \\
\hline Urban & 1 , if respondent lives in the Urban; 0 , otherwise. \\
\hline Education categories & See appendix 3 \\
\hline Married & 1 , if currently married; 0 , otherwise. \\
\hline Minority & 1 , if respondent is not belong to Han people; 0 , otherwise. \\
\hline Smoking Quitter & 1 , if respondent ever smoked but has quitted; 0 , otherwise. \\
\hline Current Smoker & 1 , if respondent smokes now; 0 , otherwise \\
\hline Overweight & 1, if BMI of respondent is greater than or equal to $25 \mathrm{~kg} / \mathrm{m}^{2}$ and less than $30 \mathrm{~kg} / \mathrm{m} 2 ; 0$, otherwise. \\
\hline Obesity & 1, if BMI of respondent is greater than or equal to $30 \mathrm{~kg} / \mathrm{m}^{2} ; 0$, otherwise. \\
\hline Heavy Drinking & 1, if respondent drinks 3 times or more per week; 0 , otherwise. \\
\hline Per Capita Income (yuan/year) & Income per capita per year (nominal), from the imputed data of income. \\
\hline Having Medical Insurance & 1 , if respondent has any kind of medical insurance; 0 , otherwise. \\
\hline \multicolumn{2}{|l|}{ Medical Facility(Community level ) } \\
\hline \multicolumn{2}{|l|}{$\begin{array}{l}\text { The Nearest Facility is a } \\
\text { beyond- county Level }\end{array}$} \\
\hline Hospital & 1 , if the nearest facility is a beyond-county level hospital; 0 , otherwise \\
\hline \multicolumn{2}{|l|}{ The Nearest Medical Facility } \\
\hline is within Community & 1 , if the nearest medical facility is located within community; 0 , otherwise. \\
\hline \multicolumn{2}{|l|}{ Distance $(\mathrm{Km})$ to the Nearest } \\
\hline Medical Facility & Distance to the nearest medical facility which the community's people usually use. \\
\hline
\end{tabular}


Appendix Table 3: Definition of Education

The respondents are asked : How many years of formal education have you completed in a regular school?

\begin{tabular}{|c|c|c|c|c|}
\hline & & & \multicolumn{2}{|c|}{ Years of Education Categories } \\
\hline \multirow{22}{*}{ If he choose } & no education completed & & 0 & Illiterates \\
\hline & 1 year primary school & & 1 & \multirow{6}{*}{ Primary school } \\
\hline & 2 year primary school & & 2 & \\
\hline & 3 year primary school & & 3 & \\
\hline & 4 year primary school & & 4 & \\
\hline & 5 year primary school & & 5 & \\
\hline & 6 year primary school & & 6 & \\
\hline & 1 year junior high school & & 7 & \multirow{3}{*}{ Junior high school } \\
\hline & 2 year junior high school & & 8 & \\
\hline & 3 year junior high school & & 9 & \\
\hline & 1 year senior high school & \multirow{12}{*}{$\begin{array}{l}\text { then we define } \\
\text { education as }\end{array}$} & 10 & \multirow{12}{*}{ Senior high school and above } \\
\hline & 2 year senior high school & & 11 & \\
\hline & 3 year senior high school & & 12 & \\
\hline & 1 year technical school & & 10 & \\
\hline & 2 year technical school & & 11 & \\
\hline & 3 year technical school & & 12 & \\
\hline & 1 year college/university & & 13 & \\
\hline & 2 year college/university & & 14 & \\
\hline & 3 year college/university & & 15 & \\
\hline & 4 year college/university & & 16 & \\
\hline & 5 year college/university & & 17 & \\
\hline & 6 years college/university or more & & 18 & \\
\hline
\end{tabular}


Appendix Table 4: Probit Model on Risk Factors

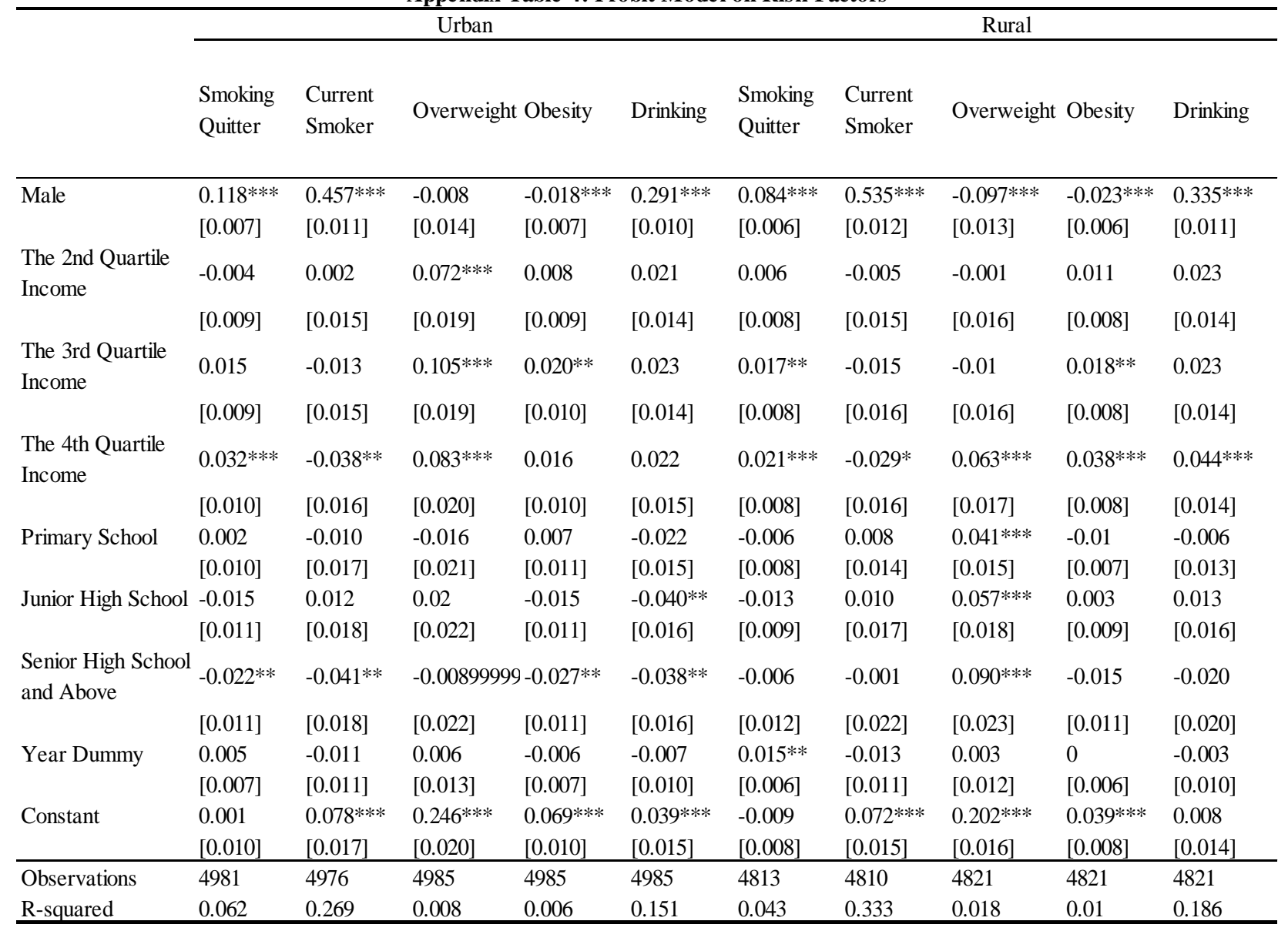

Source: CHNS, 2004 and 2006, age 45-80

Note: 1 . ${ }^{*}$ significant at $10 \%$; ** significant at $5 \%$; *** significant at $1 \%$.

2. Marginal effects reported. Standard errors in brackets.

3. Drinking-Heavy Drinking; Distance-Distance to the most popular Medical Facility; Insurance-Dummy of Having Medical Insurances; Hospital-Nearest Medical Facility is a beyond-county Level Hospital; Local-Having Medical Facility Within Community; Distance-Distance to the Nearest Medical Facility 
Appendix Table 5: WHO Estimate of BMI

\begin{tabular}{|c|c|c|c|c|c|}
\hline \multirow[b]{2}{*}{ Measures } & \multirow[b]{2}{*}{ Year } & \multicolumn{2}{|l|}{ China } & \multicolumn{2}{|l|}{ USA } \\
\hline & & Male & Female & Male & Female \\
\hline \multirow{4}{*}{ Mean BMI $\left(\mathrm{kg} / \mathrm{m}^{2)}\right.$} & 2002 & 23.4 & 23 & 28.5 & 29.2 \\
\hline & 2005 & 23.7 & 23.2 & 29 & 29.8 \\
\hline & 2010 & 24.6 & 23.9 & 30 & 30.8 \\
\hline & 2015 & 25.6 & 24.6 & 31 & 31.9 \\
\hline \multirow{4}{*}{$\mathrm{BMI}>=25 \mathrm{~kg} / \mathrm{m}^{2}$} & 2002 & 28.9 & 28.1 & 76.3 & 74.7 \\
\hline & 2005 & 33.7 & 30.1 & 79.3 & 77 \\
\hline & 2010 & 45.3 & 37.9 & 83.5 & 80.4 \\
\hline & 2015 & 57 & 45.8 & 86.9 & 83.3 \\
\hline \multirow{4}{*}{$\mathrm{BMI}>=30 \mathrm{~kg} / \mathrm{m}^{2}$} & 2002 & 1.2 & 2.2 & 37.6 & 44.7 \\
\hline & 2005 & 1.8 & 2.6 & 42.3 & 48.6 \\
\hline & 2010 & 4.5 & 5 & 50 & 54.8 \\
\hline & 2015 & 9.4 & 8.6 & 57.2 & 60.3 \\
\hline
\end{tabular}

